\title{
El uso de la cal en la construcción durante la Prehistoria reciente: nuevas aportaciones para el levante de la península Ibérica
}

\author{
The use of lime in building tasks during recent Prehistory: \\ new evidence in Eastern Iberian peninsula
}

\author{
Francisco Javier Jover Maestrea, María Pastor Quilesa, Isidro Martínez Mirab y Eduardo Vilaplana Ortego ${ }^{\mathrm{b}}$ \\ a Instituto Universitario de Investigación en Arqueología y Patrimonio Histórico. Universidad de Alicante \\ b Departamento de Química Inorgánica e Instituto de Materiales de la Universidad de Alicante (IUMA) \\ email: javier.jover@ua.es; m.pastor@ua.es; isidro@ua.es; e.vilaplana@ua.es
}

\begin{abstract}
RESUMEN
El empleo de la cal en labores constructivas durante la Prehistoria reciente en la cuenca mediterránea constituye una de las cuestiones más relevantes del proceso investigador en las últimas décadas. Las dificultades para determinar con fiabilidad la presencia de cal antrópica entre los materiales constructivos procedentes de contextos arqueológicos se han puesto de manifiesto en diversos estudios. Es de gran importancia identificar este producto pirotecnológico en las construcciones prehistóricas, diferenciándolo del carbonato cálcico natural, dadas las implicaciones sociales y medioambientales que suponen su producción y empleo. La aplicación de un amplio protocolo de análisis a un conjunto de muestras procedentes de diversos asentamientos del VI al II milenio cal BC del Levante de la península Ibérica, ha posibilitado abordar dicho problema y proponer la posibilidad del empleo de la cal desde momentos avanzados del III milenio cal BC y, con mayor seguridad, desde el II milenio cal BC.
\end{abstract}

Palabras clave: cal; pirotecnología; protocolo experimental; desarrollo social; Levante peninsular.

\begin{abstract}
The uses of lime in building tasks in the Late Prehistory along the Mediterranean area, constitutes one of the most relevant questions in the research process in the last decades. The important difficulties to determine with reliability the presence of anthropic lime among the building materials obtained from the archeological places is been commented in different studies. To identify this pyrotechnological product in the prehistoric constructions, distinguishing it from natural lime, is really important due to the social and environmental implications that its uses and production involve. The application of an ample analysis protocol to several samples coming from different human settlements of the VI to II millennium cal BC in the East of the Iberian peninsula, allow us to suggest the use of lime from early stages of the III millennium cal BC, and with more certainty, from II millennium cal BC.
\end{abstract}

Keywords: lime; pyrotechnology; experimental protocol; social development; Eastern Iberian peninsula.

Recibido: 05-10-2015. Aceptado: 17-02-2016.

Cómo citar este artículo / Citation

Jover, F. J., Pastor, M., Martínez, I., Vilaplana, E., 2016: "El uso de la cal en la construcción durante la Prehistoria reciente: nuevas aportaciones para el levante de la Península Ibérica, Arqueología de la Arquitectura, 13: e039. doi: http://dx.doi.org/10.3989/arq.arqt.2016.005

\section{Copyright}

(c) 2016 CSIC. Este es un artículo de acceso abierto distribuido bajo los términos de una licencia de uso y distribución Creative Commons Attribution (CC-by) España 3.0. 


\section{INTRODUCCIÓN}

Los avances en las técnicas de registro y análisis del conjunto de las evidencias documentadas en los procesos de excavación vienen posibilitando la realización de nuevas preguntas sobre las sociedades prehistóricas, entre las que destacan las relacionadas con la arquitectura prehistórica y, en concreto, las basadas en la descripción física y contextual de las edificaciones que fueron construidas con diferentes tipos de materiales, utilizando primordialmente la tierra (Aurenche 1981; De Chazelles y Poupet 1985; Bardou y Arzoumanian 1986; De Chazelles y Klein 2003; Vela 2003; Viñuales, Martins, Flores y Silvio 2003; De Chazelles, Klein y Pousthomis 2011; Daneels y Guerrero 2011 y 2013; Maldonado y Vela 2011; Gama-Castro, Cruz y Cruz, PiPuig, Alcalá-Martínez, Cabadas-Báez, Jasso-Castañeda, Díaz-Ortega, Sánchez-Pérez, López-Aguilar, Vilanova de Allende 2012; entre otros).

En este sentido, uno de los avances más destacados en relación con las técnicas constructivas durante la Prehistoria reciente fue la producción y el uso de la cal como material aglomerante (Hobbs y Siddall 2011: 34), ya sea en la elaboración de morteros, ya sea en recubrimientos de pavimentos, cubiertas o alzados, también con funciones decorativas. Así, con mucha probabilidad, la cal o el yeso fueron los primeros productos fruto de la alteración química intencional (Brysbaert 2007: 30).

La producción y el uso de la cal de forma generalizada supusieron importantes mejoras en la impermeabilización, durabilidad y salubridad de las viviendas (Guerrero 2007; Russell y Dahlin 2007: 407; Goren y Goring-Morris 2008; Guerrero, Soria y García 2010; Rodríguez-Navarro 2012: 91; Villaseñor y Barba 2012), lo que implicaría avances en las condiciones materiales de una importancia similar a la que pudo suponer la aplicación de la tecnología del fuego sobre el barro para la producción de ladrillos o tejas, algo introducido en la península Ibérica ya en época romana, lo que en ninguno de los dos casos tuvo necesariamente que implicar el abandono de otras técnicas tradicionales y habituales de construcción.

Ahora bien, el problema central en relación con la cal reside en determinar cuándo se comenzó a utilizar de forma generalizada y, mucho más específicamente, en cómo identificar la presencia de cal antrópica o de carácter intencional en un mortero o revestimiento de una estructura. En relación a la primera cuestión, las técnicas de fabricación de la cal parecen originarse en
Anatolia - ca. 15.000 BP-, irradiándose hacia la costa siriopalestina, donde durante el Natufiense temprano -10.300-8.500 BC - se habría empleado por primera vez la cal en la arquitectura ( Frierman 1971; Kingery, Vandiver y Prickett 1988). Durante el VII-VI milenio cal BC parece producirse una expansión del uso de la cal, sobre todo, en la construcción de finos suelos, extendiéndose a otras regiones limítrofes como Chipre (Philokyprou 2012), Grecia (Karkanas 2007: 775-796; Karkanas y Stratouli 2008: 27-41) o en los suelos de la fase III de Lepenski Vir (Serbia) (Nandris 1988: 14-15; Rusu 2011: 7-22). No obstante, para estos momentos, ya se conocía también la tecnología del yeso, creándose grandes áreas culturales en las que predominan uno de los dos materiales, aunque parece que no suelen convivir: en el Levante siriopalestino, Anatolia y Grecia predomina la cal, mientras que en el área del Tigris y el Eufrates, el yeso. Por el contrario, en Egipto parecen convivir ambas tecnologías (Philokyprou 2012: 173; Bar-Yosef y Goring-Morris 1977; Kingery, Vandiver y Prickett 1988). Por lo que respecta a la península Ibérica, el inicio del empleo de la cal tradicionalmente ha sido ligado a la presencia de los fenicios y al proceso de copelación de la plata hacia el siglo VII BC (Díes 1994; Blázquez 2008: 26-27).

Con la intención de contestar a estas cuestiones, en el presente artículo exponemos, en primer lugar, los problemas analíticos inherentes a la constatación del empleo de la cal, proponiendo un protocolo de análisis físico-químico para su determinación. Y, en segundo lugar, como caso de estudio, presentaremos los análisis efectuados en un conjunto de muestras procedentes de distintos asentamientos del Levante de la península Ibérica, abarcando un espectro cronológico desde el VI hasta el II milenio cal BC, con el objeto de contribuir a fijar el momento a partir del que se constatan la producción y uso intencional de la cal en labores constructivas.

\section{¿CÓMO DETERMINAR LA PRESENCIA DE CAL ANTRÓPICA?}

A la hora de abordar el estudio arqueológico de la utilización de la cal en los morteros constructivos, en primer lugar es necesario diferenciar la presencia de carbonato cálcico natural respecto de la cal en sí, un producto de origen antrópico.

El carbonato cálcico es un compuesto químico abundante en la naturaleza, y omnipresente en todos los 
yacimientos arqueológicos. Es el componente principal de rocas calcáreas, aunque también está presente, por ejemplo, en moluscos. Así, presenta diferentes polimorfos: calcita, aragonito, vaterita, monohidrocalcita, ikaita y carbonato cálcico amorfo. De todos ellos, la calcita $\mathrm{y}$, en menor medida, el aragonito son los más habituales. En los yacimientos arqueológicos, la calcita puede tener tres posibles orígenes: geológico, biológico y pirotecnológico (Fig. 1). El aragonito suele presentar un origen biológico, aunque en determinadas condiciones éste también podría ser pirotecnológico (Weiner 2010: 76-77).

Por el contrario, la cal es óxido de calcio resultado de un proceso antrópico. Se obtiene generalmente de la calcinación de la piedra caliza a altas temperaturas, que varían entre unos $650-900{ }^{\circ} \mathrm{C}$. Puede ser utilizada tanto viva, como apagada o hidratada. Es una sustancia alcalina que presenta un tacto liso y gran dureza, generalmente de color blanco, aunque también puede ser amarillento o gris.

Una aproximación macroscópica, mediante la observación directa, no permite determinar con seguridad la presencia de cal en morteros arqueológicos. Es necesario llevar a cabo estudios microvisuales mediante la aplicación de técnicas experimentales físico-químicas. No obstante, la detección de cal en los morteros constructivos de momentos prehistóricos, valiéndose de este procedimiento, ofrece asimismo considerables dificultades, en comparación con la determinación de la cal en morteros estandarizados, habituales fundamentalmente en cronologías posteriores. En el caso de contener cal, los morteros de tierra prehistóricos suelen presentarla en cantidades bajas y variables, y en combinación con elementos añadidos a la tierra de muy diversa naturaleza, incluidos restos de piedras calizas naturales u otros materiales con contenido en calcita. La presencia de restos de piedra caliza con evidencias de combustión en el interior de los morteros no significaría per se el uso intencional de la cal en los mismos, pues podrían haber sido añadidos accidentalmente.

Dentro de los entornos arqueológicos existen dos fuentes principales de calcita de origen pirotecnológico: la combustión de materia vegetal y la producción de cal a partir de diferentes rocas calcáreas, como la calcita, el aragonito, la caliza o el mármol, o incluso de conchas marinas (Brysbaert 2007) o corales (Carran, Hughes, Leslie y Kennedy 2011: 135; Hobbs y Siddall 2011: 41). En ambos casos, y dependiendo de la temperatura final alcanzada, se produce óxido de calcio $(\mathrm{CaO})$. En el primer caso, cuando la combustión de la materia vegetal alcanza una temperatura de entre $430-510^{\circ} \mathrm{C}$, el oxalato cálcico de esta materia se convierte en carbonato cálcico. En ambos procesos este compuesto se descompone al alcanzar los $800^{\circ} \mathrm{C}$, temperatura variable en función de las circunstancias, formando $\mathrm{CaO}$. En el caso de la combustión de la materia vegetal, el óxido reacciona con el $\mathrm{CO}_{2}$ de la atmósfera y formará carbonato cálcico. En el caso de la cal, se mezclará con agua formando hidróxido cálcico $(\mathrm{CaOH})$ que, una vez seco, reaccionará también con el $\mathrm{CO}_{2}$ atmosférico, para formar carbonato cálcico. De este modo, los dos procesos son químicamente muy similares (Karkanas 2007: 776; Vilaplana, Martínez, Such y Juan 2011: 276) y ambos carbonatos cálcicos recarbonatados, así como el de partida, presentan la misma fórmula química $\left(\mathrm{CaCO}^{3}\right)$, pero diferentes formas y tamaños de partícula (Goren y Goldberg 1991: 132; Boynton 1980).
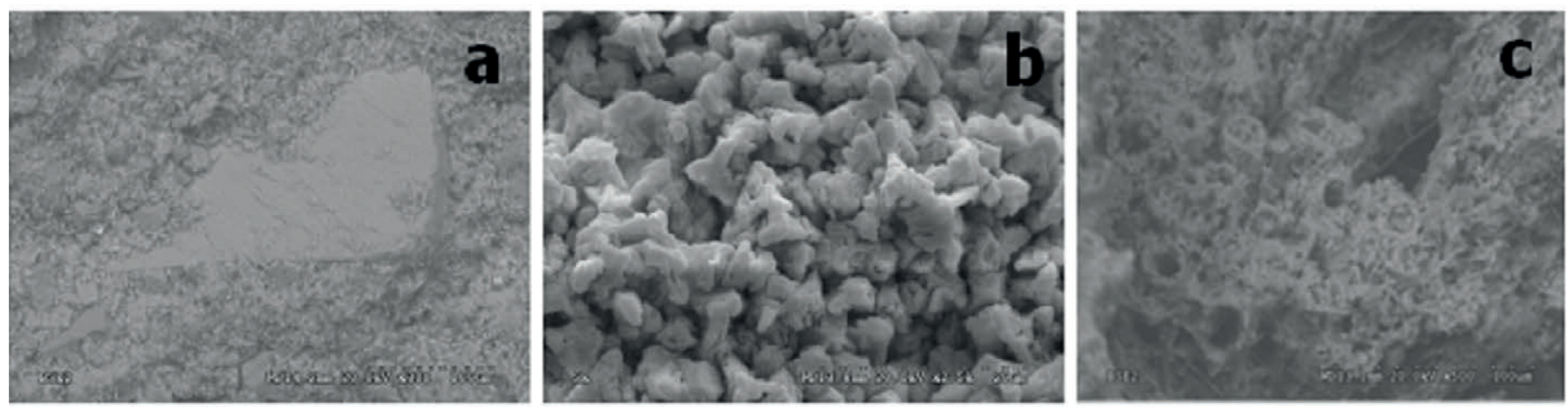

Fig. 1. Microfotografías SEM: a) Carbonato cálcico de origen geológico de Benàmer, UE 1017, 300X; b) Cristales de carbonato cálcico recarbonatado de origen pirotecnológico de Benàmer, UE 1017, recubierta de Au, 2500X y c) Carbonato cálcico de origen biológico: colonia de Rivularias, corte transversal de filamentos mostrando los huecos de los tricomas de Benàmer, UE 2130, 500x. 
Lo anteriormente expuesto hace que una aproximación macroscópica, mediante la observación directa, no permita determinar con seguridad la presencia de cal en morteros arqueológicos. Para ello es necesario llevar a cabo estudios microvisuales, mediante la aplicación de técnicas experimentales físico-químicas. Tampoco un análisis químico elemental, como la fluorescencia de rayos X (FRX), o un análisis de los componentes minerales presentes en las muestras - a partir de la identificación de sus fases cristalinas-, mediante difracción de rayos $\mathrm{X}(\mathrm{DRX})$, son determinantes a la hora de dilucidar el origen de los diferentes tipos de calcita (Martínez y Vilaplana 2010: 124).

Con el fin de abordar la presencia de la cal en la composición de restos de morteros constructivos prehistóricos se ha aplicado en distintos trabajos de las últimas décadas, un análisis mediante difracción de rayos X (DRX). Esta técnica puede revelar la presencia, por ejemplo, del mineral de calcita, con contenido en carbonato cálcico. No obstante, este análisis cristalográfico no proporciona información acerca de fases amorfas u orgánicas (Martínez y Vilaplana 2010: 124). A modo de ejemplo, la DRX ha sido empleada en restos constructivos procedentes de los yacimientos argáricos del Rincón de Almendricos y del Cerro de las Viñas de Coy (Lorca, Murcia), interpretados como enlucidos, en los que se observaban distintas capas distinguibles por su diferente coloración. En la composición de los fragmentos procedentes de ambos yacimientos se halló, mediante DRX, carbonato cálcico asociado a la presencia del mineral calcita, aunque no óxido de calcio. Los autores afirmaron que los constructores de las estructuras argáricas analizadas podrían haber conocido y aplicado la tecnología de la cal, pero que el óxido de calcio no se halló en los enlucidos al haberse transformado en carbonato cálcico, probablemente, mediante procesos postdeposicionales (Ayala y Ortiz 1989). Asimismo, en un estudio macrovisual de los restos constructivos de barro con improntas vegetales del Rincón de Almendricos, interpretados como pertenecientes a alzados y techumbres, se afirmaba que una parte de ellos estarían enlucidos con cal en su cara externa (Ayala, Rivera y Obón de Castro 1989: 282).

Ante los problemas de identificación descritos, creemos necesario aplicar un protocolo de análisis integrado por diversas técnicas con las que poder diferenciar claramente la cal intencional o antrópica, de los carbonatos cálcicos de origen geológico o biológico.

\section{A MODO DE PROPUESTA: EL PROTOCOLO DE ANÁLISIS FÍSICO- QUÍMICO}

Con el fin de poder determinar la presencia de cal como producto originado en una combustión antrópica intencional, proponemos el uso conjunto de una serie de técnicas experimentales (Fig. 2), siguiendo la propuesta de Middendorf, Hughes, Callebaut, Baronio y Papayianni (2005) para el estudio de morteros antiguos. Consiste en la aplicación conjunta de cinco técnicas diferentes y complementarias, que intervienen escasamente sobre las muestras analizadas, al requerir una cantidad reducida de ellas. Los tratamientos se limitan a una molienda manual en un mortero de ágata, y sólo en el caso de las láminas delgadas el proceso es más laborioso.

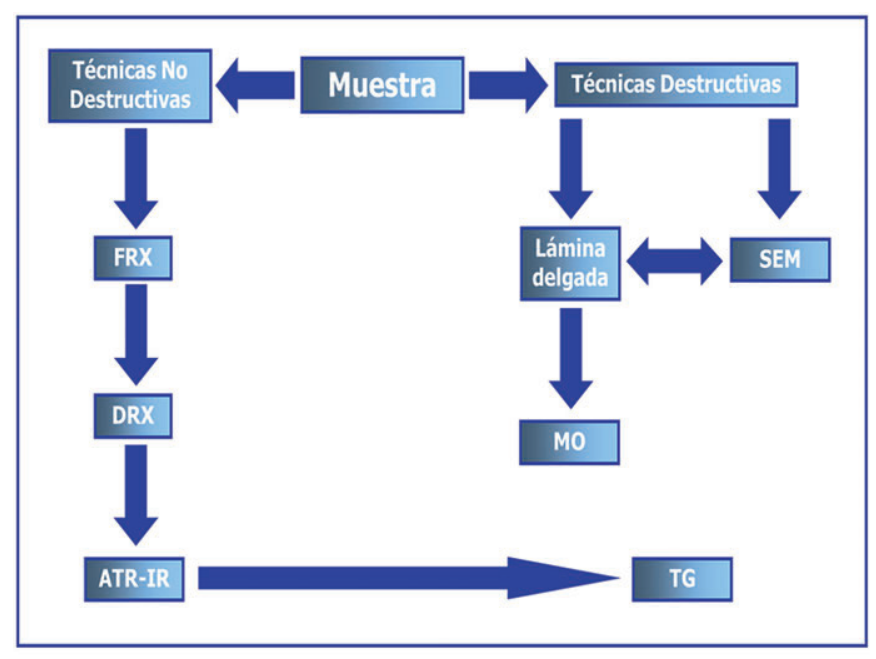

Fig. 2. Secuenciación en la aplicación de las técnicas instrumentales.

A continuación, pasamos a exponer de forma concisa las técnicas experimentales que conforman el protocolo de análisis seguido, según su orden de aplicación, partiendo de aquéllas que no destruyen la muestra. Dicho protocolo se concreta en:

A. Documentación gráfica. Como punto de partida, se establece la documentación gráfica mediante fotografía digital de la muestra a analizar. El segundo paso sería su observación, mediante una lupa equipada con una cámara digital. Esto nos permite una primera e importante aproximación, que nos guiará en las siguientes fases.

B. Fluorescencia de rayos X (FRX). Consiste en un análisis químico elemental, tanto cualitativo como 
cuantitativo, con el objetivo de conocer la composición química de los restos arqueológicos analizados. Esta primera aproximación resulta de utilidad para la interpretación posterior de los datos obtenidos en los análisis que se realizarán a continuación. Este análisis requiere la toma de una pequeña porción de muestra. En algunos casos, en los que no sea posible la toma de muestras, puede ser necesaria la microfluorescencia de rayos $X(\mu \mathrm{FRX})$, que no precisa ninguna preparación (Martínez, Vilaplana, Such, Juan y García 2014: 341).

C. Difracción de rayos X (DRX). Se trata de un análisis destinado a determinar los componentes minerales presentes en los restos, a partir de la identificación de fases cristalinas, aunque con bajo nivel de detección. Como ya se ha indicado, este análisis cristalográfico no aporta datos sobre fases amorfas u orgánicas (Martínez, Vilaplana, Such, Juan y García 2014). Permite determinar el tamaño de los cristales y obtener parámetros de la red. Para este análisis utilizamos la misma porción de muestra usada en la FRX.

D. Espectroscopía infrarroja, por transformada de Fourier en modo de transmisión (FT-IR) o mediante reflectancia total atenuada (ATR-IR). La aplicación de estas técnicas complementa los resultados de los análisis de DRX, al permitir la identificación de materia orgánica y de fases amorfas en las muestras analizadas (Martínez, Vilaplana, Juan, Such y Cazorla 2012: 3). En nuestra opinión, la segunda técnica presenta ventajas sobre la primera, ya que mediante la aplicación de ATR-IR la muestra no requiere preparación ni sufre ninguna alteración, lo que supone un ahorro económico y de tiempo. Del mismo modo, al no manipularse, ésta no se contamina y, además, puede volver a utilizarse en caso de ser necesario repetir el análisis o aplicar otras técnicas posteriormente. Como desventaja, en la ATR-IR es necesaria una mayor cantidad de muestra, unos $20 \mathrm{mg}$, frente a los $2 \mathrm{mg}$ necesarios para la FT-IR. En estas técnicas se usa la misma porción de muestra utilizada para las dos analíticas anteriores (FRX y DRX).

Según Chu, Regev, Weiner y Boaretto (2008: 905-911) y Regev, Poduska, Addadi, Weiner y Boaretto (2010: 3022-3029), la relación entre las bandas $v_{2} / v_{4}$ de la calcita refleja el orden de su estructura cristalina, lo que puede permitir diferenciar sus orígenes ya que, para la calcita de origen geológico, su valor se sitúa alrededor de 3, mientras que en enlucidos modernos está en 6,5 y en los arqueológicos entre 3 y 6,5. La ratio tan elevada es indicativa de un cristal desordenado, lo que implica su formación a partir de óxido cálcico formado a alta temperatura. Por tanto, el uso de esta técnica nos podría permitir una primera aproximación al origen de la calcita en las muestras analizadas.

E. Termogravimetría y análisis térmico diferencial (TGATD). Estos análisis proporcionan termogramas o curvas de temperatura, que recogen el comportamiento de las muestras al aplicarles un aumento lineal de temperatura. Mediante ellas se puede determinar el grado de humedad, la presencia de yeso o calcita en la composición o el rango de temperatura - temperaturas de inicio y finalización - de los procesos de descomposición térmica de estos compuestos (Martínez, Vilaplana, Juan, Such y Cazorla 2012: 2). La implementación de estas técnicas mediante su acople a un espectrómetro de masas (TG-MS) nos permite registrar cómo evoluciona la emisión de gases, tales como $\mathrm{CO}, \mathrm{CO}_{2}$ o vapor de $\mathrm{H}_{2} \mathrm{O}$, por parte de la muestra, durante su proceso de descomposición térmica (Vilaplana, Such, Juan y García 2014: 82). Esto implica una mejora a la hora de interpretar las curvas, al delimitar mejor las pérdidas de peso producidas al calentarse la muestra que, en ocasiones, se han interpretado de manera errónea. Esta es una técnica destructiva, aunque necesita muy poca cantidad de muestra - ca. 20 $\mathrm{mg}$ - y para ella utilizamos la porción ya utilizada en los análisis anteriores. Si la calcita analizada mediante esta técnica proviene de la recarbonatación de un hidróxido cálcico — cal hidratada-, su temperatura de descomposición será inferior a la del carbonato cálcico original de partida. Esta variación parece estar relacionada con que, tras la recarbonatación, el tamaño de los cristales del nuevo carbonato formado es inferior a los del carbonato de partida (Webb y Krüger 1970: 317). Según esta idea, podríamos diferenciar la calcita pirogénica de la geológica. Ahora bien, estas temperaturas varían según las diferentes condiciones de análisis empleadas: velocidad de calentamiento, peso de la muestra, tamaño de partícula de la muestra, atmósfera empleada, etc. (Wendlant 1986: 12; Bish y Duffy 1990: 116-118), por lo que es difícil poder diferenciarlas adecuadamente.

F. Microscopías: electrónica de barrido unida a una sonda de energía dispersiva de rayos X (SEM-EDX) y óptica de transmisión (MOT). Con ellas analizamos las superficies de las muestras, tanto si éstas están "frescas", como sobre lámina delgada. Este último análisis requiere el uso de una cierta porción de la 
muestra, pero a cambio, nos permite observar su homogeneidad, lo que mejora la fiabilidad de los datos obtenidos, al poder hacerlos extensivos a la totalidad de la muestra analizada. La microscopía puede aportar información en cuanto a la determinación de la cal antropogénica, ya que los cristales del carbonato de calcio formado tras la combustión de la piedra caliza son de menor tamaño y diferente morfología que los de origen natural (Goren y Goldberg, 1991: 132).

La aplicación de este protocolo, frente al empleo aislado de cada una de las técnicas, permite determinar con mayor fiabilidad el empleo de cal intencional, así como documentar diferentes formas de aparición de cal no intencional o biogénica en los compuestos. No obstante, la identificación tampoco está exenta de problemas.

\section{EL LEVANTE DE LA PENÍNSULA IBÉRICA COMO EJEMPLO: DE LOS PRIMEROS ASENTAMIENTOS AGRÍCOLAS A LAS COMUNIDADES CAMPESINAS ESTABLES DE LA EDAD DEL BRONCE}

Dentro de la península Ibérica, las tierras centrales y meridionales valencianas constituyen uno de los espacios geográficos mejor conocidos en cuanto a la Prehistoria reciente se refiere. Una dilatada trayectoria investigadora y el desarrollo, en las últimas décadas, de un diverso número de proyectos de investigación y de excavaciones arqueológicas, han permitido contar con un destacado registro de asentamientos al aire libre correspondientes a comunidades agropecuarias, presentes desde mediados del VI milenio cal BC (Bernabeu, Molina, Diez y OrozcoKöhler 2006; Bernabeu, Molina, Orozco-Köhler y Diez 2008; García Atiénzar 2009; García Atiénzar y Jover 2011; Martí y Bernabeu 2012). La consolidación de aquellas prístinas sociedades agricultoras y su expansión por la península Ibérica (Bernabeu, Barton, Pardo y Bergin 2015), permitió el surgimiento y crecimiento de nuevas entidades sociales que alcanzaron un importante desarrollo a partir de finales del III milenio cal BC, observable en la complejidad de los asentamientos construidos a base de piedra, madera y tierra (De Pedro 1998; Jover y López 2009; Machado, Jover y López 2009).

En este sentido, conviene resaltar que, desde los primeros momentos del neolítico, se han documentado edificios de carácter doméstico de diversas plantas, tanto rectangulares con extremos absidales, como la documentada en Mas d'Is (Bernabeu, Orozco-Köhler, Diez, Gómez y Molina 2003; Martí y Bernabeu 2012), como los fondos de cabaña de tendencia circular u oval, registrados en Benàmer (Jover 2013) o en El Tossal de Les Basses de Alicante (Rosser y Fuentes 2007). Durante el IV y III milenio cal $\mathrm{BC}$, las evidencias muestran una presencia de fondos de cabaña o cabañas con zócalos de piedra con planta de tendencia circular, como se constata en asentamientos como la Illeta dels Banyets (Soler Díaz 2006) y Arenal de la Costa (Bernabeu 1993). Por su parte, a partir de finales del III milenio cal BC, se documenta, por primera vez, la edificación de asentamientos con zócalos de piedra, madera y tierra en lo alto de crestas montañosas y cimas de cerros. Ejemplos significativos son yacimientos campaniformes como el Peñón de la Zorra (García Atiénzar 2014), o poblados de la Edad del Bronce como Lloma de Betxí (De Pedro 1998), Terlinques (Jover y López 2009) o Cabezo Pardo (López 2014).

De los prístinos asentamientos neolíticos se cuenta con el registro de parte de uno de ellos, Benàmer (Muro d'Alcoi, Alicante) (Torregrosa, Jover y López 2011) (Fig. 3), ubicado en el curso medio del río Serpis, el cual presentaba una secuencia de ocupación en la que se distinguieron, al menos, cinco fases. De ellas, aquí nos interesan las fases II y IV. La fase II, localizada en el sector 1, se corresponde con la documentación de lo que se ha interpretado como un área de hábitat de un grupo cardial de la segunda mitad del VI milenio cal BC, integrado por lo que pudo ser un fondo de cabaña y diversas áreas de producción al aire libre, entre las que destaca un conjunto de estructuras de combustión (Jover 2013).

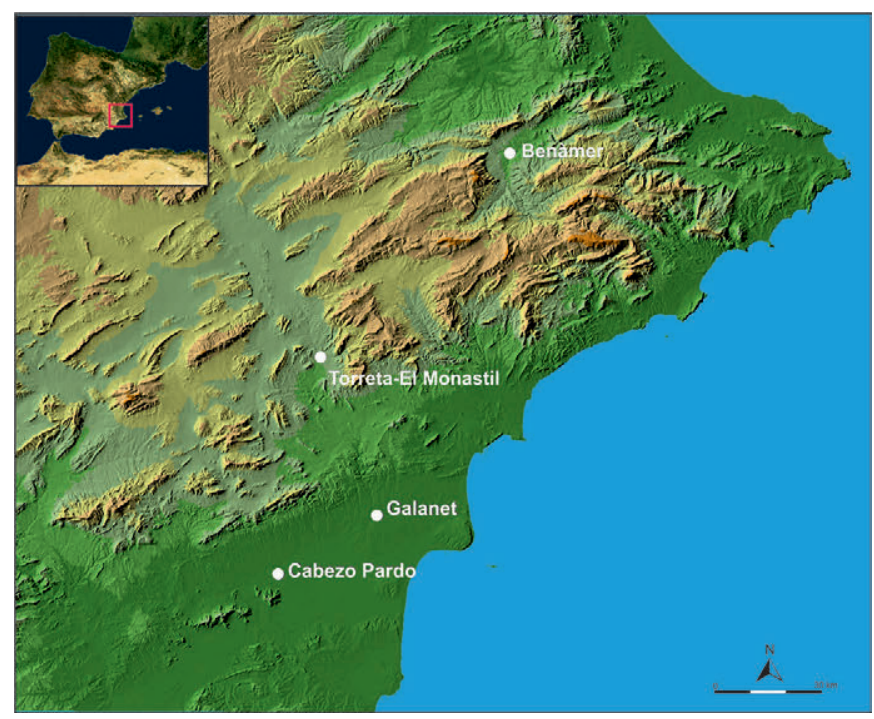

Fig. 3. Ubicación de los asentamientos de los que proceden las muestras analizadas. 
De este momento se ha analizado un fragmento de mortero o material de construcción.

En el mismo yacimiento de Benàmer, en su fase $\mathrm{IV}$, correspondiente a finales del $\mathrm{V}$ o principios del IV milenio cal BC (Fig. 4), fue localizado en el sector 2 un conjunto concentrado de más de 200 estructuras negativas de tipo silo, algunas de las cuales presentaban una especie de enlucido blanquecino de varios centímetros de espesor en sus paredes interiores. Fragmentos de las mismas también han sido analizados.

Por otra parte, también contamos con la información de dos asentamientos al aire libre del III milenio cal BC, ubicados ambos en la cuenca del río Vinalopó. El asentamiento de Galanet (Elche) (Jover, Torregrosa y García 2014), de inicios del III milenio cal BC, estaba integrado por numerosas estructuras negativas de tipo silo y foso. Vertidos en el interior de algunos silos, se documentaron algunos fragmentos de barro endurecido interpretados como restos de material constructivo (Fig. 5). Por su parte, el asentamiento de La Torreta-El Monastil (Elda) estaba integrado por silos, un foso de gran tamaño y parte del fondo de una cabaña (Jover 2010). En el interior del foso también se habían vertido gran cantidad de desechos de materiales constructivos. De un amplio conjunto de restos de barro - casi un centenar-, se seleccionaron dos de ellos.

Por último, y en relación con el II milenio cal BC, las investigaciones arqueológicas han puesto de manifiesto un denso poblamiento estable en asentamientos al aire libre de diversos tamaños pero, sobre todo, dos espacios sociales coetáneos, aunque social y culturalmente diferentes: el espacio argárico en las tierras del sur de Alicante (López 2009) y el resto del este peninsular, que se englobaría dentro del área cultural del Bronce Valenciano (Jover y López 1997, 2009). En este espacio se ha excavado en diversos asentamientos, como Terlinques, Polovar y Cabezo Redondo en el corredor de Villena, así como en el yacimiento argárico de Cabezo Pardo (López 2014). Las muestras analizadas hasta el momento y recogidas en el presente trabajo proceden de diversos edificios de este último asentamiento, cuya cronología se sitúa en la primera mitad del II milenio cal BC.

\begin{tabular}{|c|c|c|c|c|c|c|c|}
\hline YACIMIENTO & CONJUNTO & REF. LABORATORIO & BP & Cal BC 10 & Cal BC $2 \sigma$ & MUESTRA & FASE ARQ \\
\hline Benàmer & UE 1017. Sector 1 & CNA-539 & $6575 \pm 50$ & $5602-5482$ & $5617-5475$ & Agregado polen & Neolitico lA \\
\hline Galanet & UE 264 & Beta-287335 & $4320 \pm 40$ & $3010-2892$ & $3020-2880$ & Semilla Hordeum vulgare & Neoltico \|B \\
\hline Torreta-EI Monastil & Foso. UE 2 & Beta-139360 & $4270 \pm 110$ & $3081-2674$ & $3328-2504$ & Pinus halepensis & Neolitico IIB \\
\hline Cabezo Pardo & UE 3017. Uso nivel antiguo & Beta-308903 & $3590 \pm 30$ & 2008-1900 & 2028-1883 & Hueso animal & Bronce Pleno. Fase I \\
\hline Cabezo Pardo & UE 3003 & Beta- 258468 & $3530 \pm 40$ & $1921-1776$ & $1960-1750$ & Cereal & Bronce Pleno. Fase I \\
\hline Cabezo Pardo & UE 3029 & Beta-308904 & $3460 \pm 30$ & $1875-1698$ & $1881-1692$ & Hueso animal & Bronce Pleno. Fase II \\
\hline Cabezo Pardo & Tumba 1. Individuo 1 & Beta-237765 & $3460 \pm 40$ & 1876-1696 & $1889-1684$ & Hueso humano & Bronce Pleno. Fase II \\
\hline Cabezo Pardo & UH6. UE 3005 & Beta-258466 & $3440 \pm 40$ & $1870-1689$ & $1880-1650$ & Ovis aries & Bronce Pleno. Fase II \\
\hline Cabezo Pardo & Tumba 1. Individuo 2 & Beta-237766 & $3390 \pm 40$ & $1739-1635$ & $1867-1536$ & Hueso humano & Bronce Pleno. Fase ॥ \\
\hline
\end{tabular}

Fig. 4. Tabla con las dataciones radiocarbónicas de los yacimientos de los que proceden las muestras analizadas. Todas las calibraciones han sido realizadas con el programa OxCal v4.2.3. (Bronk Ramsey y Lee 2013), utilizando la curva de calibración Intcal13 (Reimer, Bard, Bayliss, Beck, Blackwell, Bronk Ramsey, Buck, Cheng, Edwards, Friedrich, Grootes, Guilderson, Haflidason, Hajdas, Hatté, Heaton, Hoffmann, Hogg, Hughen, Kaiser, Kromer, Manning, Niu, Reimer, Richards, Scott, Southon, Staff, Turney y Van der Plicht 2013).
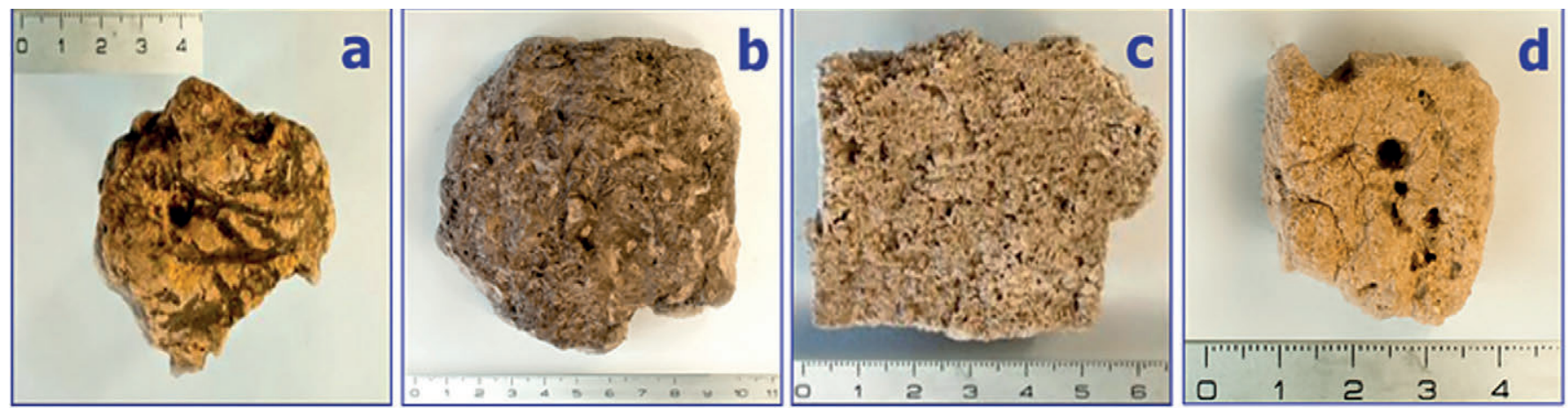

Fig. 5. Fotografía de algunos de los fragmentos constructivos analizados: (a) Benàmer, UE 1017; (b) Galanet, UE 250-1; (c) Benàmer, UE 2130; (d) Galanet, UE 250-2. 


\section{ANÁLISIS Y RESULTADOS DE LAS MUESTRAS SELECCIONADAS}

Las muestras analizadas con el objetivo de determinar la posible presencia de cal en ellas, un total de doce, pertenecen a diversos fragmentos constructivos de barro o de revestimientos. Proceden de los asentamientos señalados con diferentes cronologías, desde el Neolítico antiguo cardial hasta momentos plenos de la Edad del Bronce (Fig. 6).

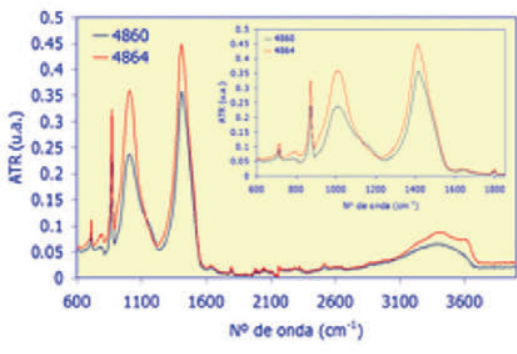

Perfiles de ATR-FTIR de las muestras 4860 y 4864 del yacimiento de la Torreta-EI Monastil (Elda, Alcante).

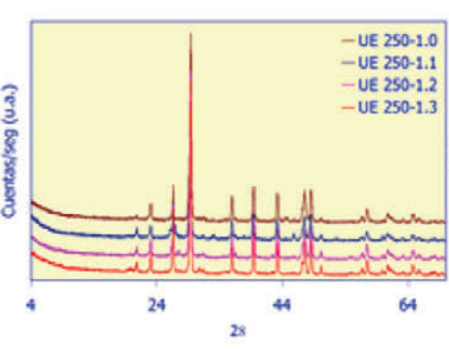

Perfiles de DRX de las muestras UE 250 del yacimiento del Galanet (Elx, Alicante).

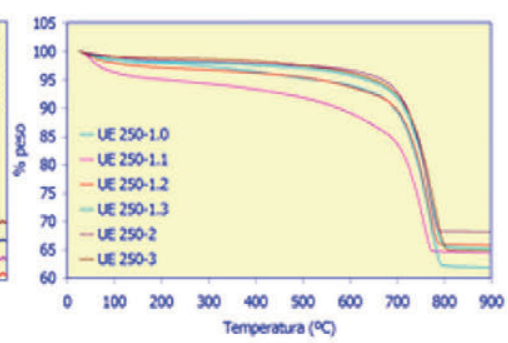

Perfiles de TG de las muestras UE 250 del yacimiento del Galanet (Elx, Alicante).

\section{FRX-ATR-DRX-TG}

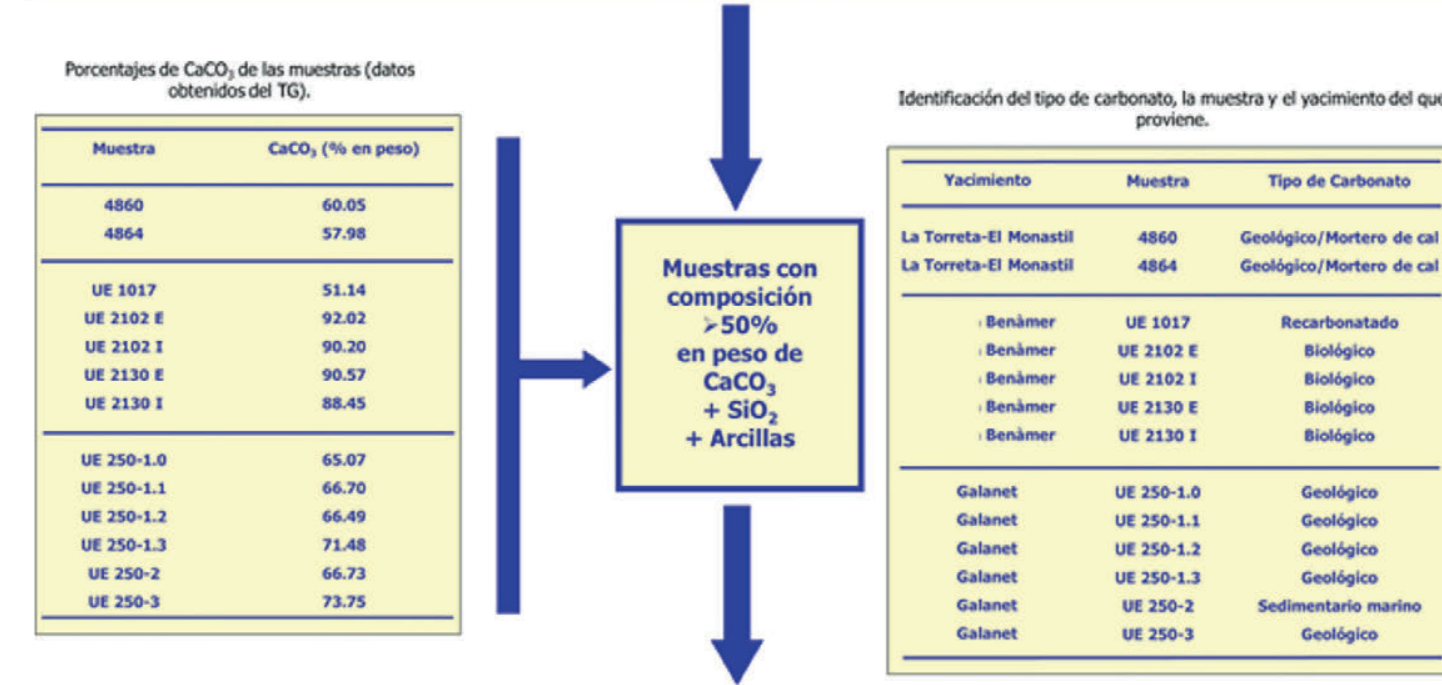

Grado de tecnología: Naturaleza del $\mathrm{CaCO}_{3}$

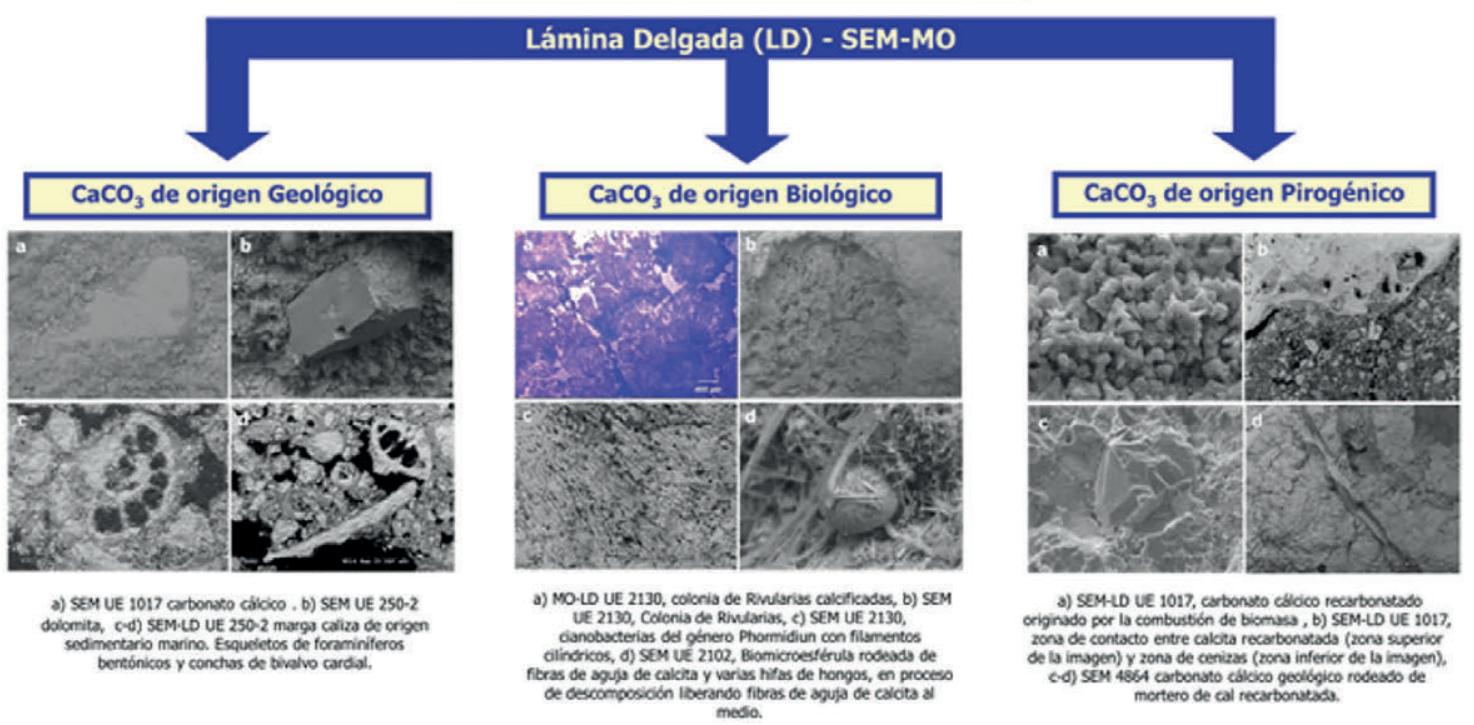

Fig. 6. Cuadro explicativo con la aplicación de las distintas técnicas aplicadas a la determinación del origen del carbonato cálcico. 
Por una parte, se aplicó el protocolo analítico señalado, integrado por cinco técnicas instrumentales FRX, DRX, ATR-IR, TG-ATD, SEM-EDX/MOT- a un fragmento de barro, interpretado como de naturaleza constructiva, procedente del asentamiento neolítico cardial de Benàmer (Muro d'Alcoi, Alicante). La muestra procede de la UE 1017, ubicada en el sector 1 del yacimiento. Se trataba de un estrato de tierra de relleno, con presencia de limos orgánicos compactos de coloración negruzca y gran cantidad de restos arqueológicos, en su mayor parte fragmentos cerámicos y productos líticos. El fragmento no presentaba improntas ni caras distinguibles. La muestra estaba compuesta principalmente por calcita, cuarzo, arcillas, así como por otros elementos como hematita, sin descartar otros óxidos/hidróxidos de hierro, o rutilo. La aplicación de ATR-IR no reveló la presencia de materia orgánica en la muestra concreta tomada, sí observándose carbón y cenizas en el fragmento mediante microscopía, que por su localización en la pieza no formarían parte de la matriz del mortero, sino que se habrían depositado sobre él. El estudio reveló la presencia de carbonato cálcico recarbonatado, pero éste habría tenido su origen en la combustión de biomasa, es decir, de cenizas y carbones presentes en la muestra, que habrían sido, probablemente, añadidos como estabilizantes a la tierra con finalidades constructivas (Vilaplana, Martínez, Such y Juan 2011).

Del mismo modo, el estudio de dos muestras procedentes del recubrimiento interno de dos silos (Fig. 7) de la fase IV del mismo yacimiento de Benàmer, ha resultado ser muy ilustrativo en cuanto a las técnicas físico-químicas que pueden aplicarse para evitar una identificación incorrecta del carbonato cálcico como cal antropogénica. Estas estructuras se asocian a la fase neolítica postcardial, datada hacia la segunda mitad del $\mathrm{V}$ milenio cal BC. Los fragmentos analizados forman parte de los revestimientos UE 2130 y UE 2101, de las estructuras negativas oval y circular UUEE 2131 y 2121, respectivamente. Se trata de dos estructuras de gran tamaño, con revestimientos de varios centímetros de espesor en sus paredes, que presentaban diferentes estratos de relleno con escaso material arqueológico. Ambos fragmentos de recubrimiento presentaban una coloración blanquecina y mostraban dos superficies paralelas, una de ellas plana y compacta, que fue interpretada como la cara interna (Torregrosa, Jover y López 2011). La determinación de la composición química mediante FRX reveló la presencia predominante de carbonato cálcico, y la aplicación de DRX y espectroscopía infrarroja ATR-IR aportó la presencia del mineral calcita, además de cuarzo y caolinita. No obstante, el empleo de microscopía, combinando la microscopía electrónica de barrido (SEM) con la óptica de transmisión (MOT), mediante láminas delgadas, determinó que la presencia de calcita era biogénica, por lo que el supuesto revestimiento de las estructuras negativas con probable contenido en cal resultó ser una mineralización y calcificación de cianobacterias, cuya composición química es mayoritariamente carbonato cálcico.

Por otra parte, del asentamiento del IV milenio cal BC de Galanet (Elche, Alicante), se ha abordado el estudio de las muestras de tres fragmentos constructivos procedentes de la UE 250, relleno de la estructura negativa circular UE 249. Se trataba de fragmentos de morteros
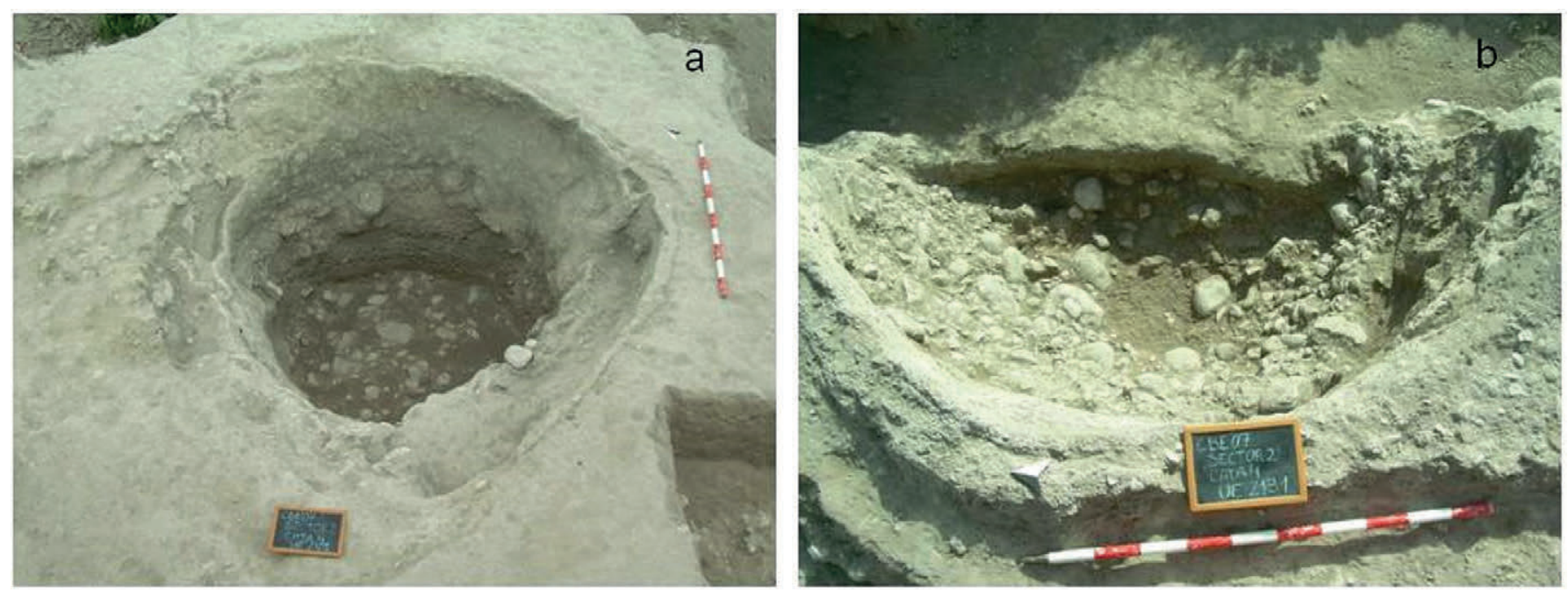

Fig. 7. Silos UE 2121 y 2131 del yacimiento de Benàmer, de los que proceden los recubrimientos analizados. 
de tierra vertidos al interior del silo como material de desecho, junto a una gran cantidad de material arqueológico. Los elementos de barro analizados no presentaban improntas vegetales que se pudieran corresponder con las de un entramado constructivo. Sí mostraban marcas de elementos vegetales desaparecidos integrados en el mortero, así como orificios que pueden corresponderse con huellas de ramas o haber sido producidos por insectos anélidos. En este caso, a las técnicas utilizadas en estudios previos se añadió la termogravimetría acoplada a un espectrómetro de masas (TG-EM). Los resultados de las distintas técnicas aplicadas proporcionaron un considerable porcentaje de carbonato cálcico en la composición de las muestras, pero no se han hallado evidencias de que se hubiera empleado cal antropogénica.

Sin embargo, la aplicación de este mismo conjunto de técnicas físico-químicas -FRX, DRX, ATR-IR, TG-ATD, SEM-EDX - a dos muestras procedentes de elementos constructivos de barro del asentamiento de la Torreta-El Monastil (Elda, Alicante) (Fig. 8), de mediados del III milenio cal BC, sí ha apuntado la posible presencia de cal antropogénica en los morteros. Los fragmentos escogidos para su análisis - muestras 4860 y 4864 - proceden del foso UE 2, donde fueron hallados un total de 96 fragmentos de similares características.

Ambos presentan coloración blanquecina, una cara plana y e improntas de sección circular generadas por elementos vegetales desaparecidos, así como diversas capas a modo de enlucidos (Fig. 9). El análisis de la composición química de los restos mediante FRX reveló óxidos de calcio, y en la composición mineral se halló calcita tras aplicar DRX, así como cuarzo y dolomita. La espectroscopía mediante reflectancia total atenuada (ATR-IR) documentó asimismo la presencia de calcita en la composición. No obstante, los análisis termogravimétricos aportaron unas curvas de temperatura de descomposición de la calcita algo inferiores a las indicadas habitualmente en la bibliografía en la producción de cal. En cualquier caso, se estableció la presencia de carbonato cálcico recarbonatado en el mortero, con fragmentos de piedra caliza sin carbonatar, que pueden deberse a que los restos estuvieran incluidos como impurezas de algún componente del mismo, pero también pueden provenir de la roca calcárea original y no haberse transformado durante el proceso de calcinación, al no alcanzarse suficiente temperatura o no haberse mantenido ésta suficiente tiempo.

Por último, el estudio realizado sobre cuatro muestras de elementos constructivos de barro procedentes del poblado argárico de Cabezo Pardo (San Isidro/ Granja de Rocamora, Alicante), situado en la primera mitad del II milenio cal BC (López 2014), ha planteado asimismo el posible uso de la cal antropogénica como revestimiento de los alzados de una estructura de su segunda fase de ocupación, cuya fecha de construcción se data en torno al 1780 cal BC (Jover, López y García-Donato 2014).
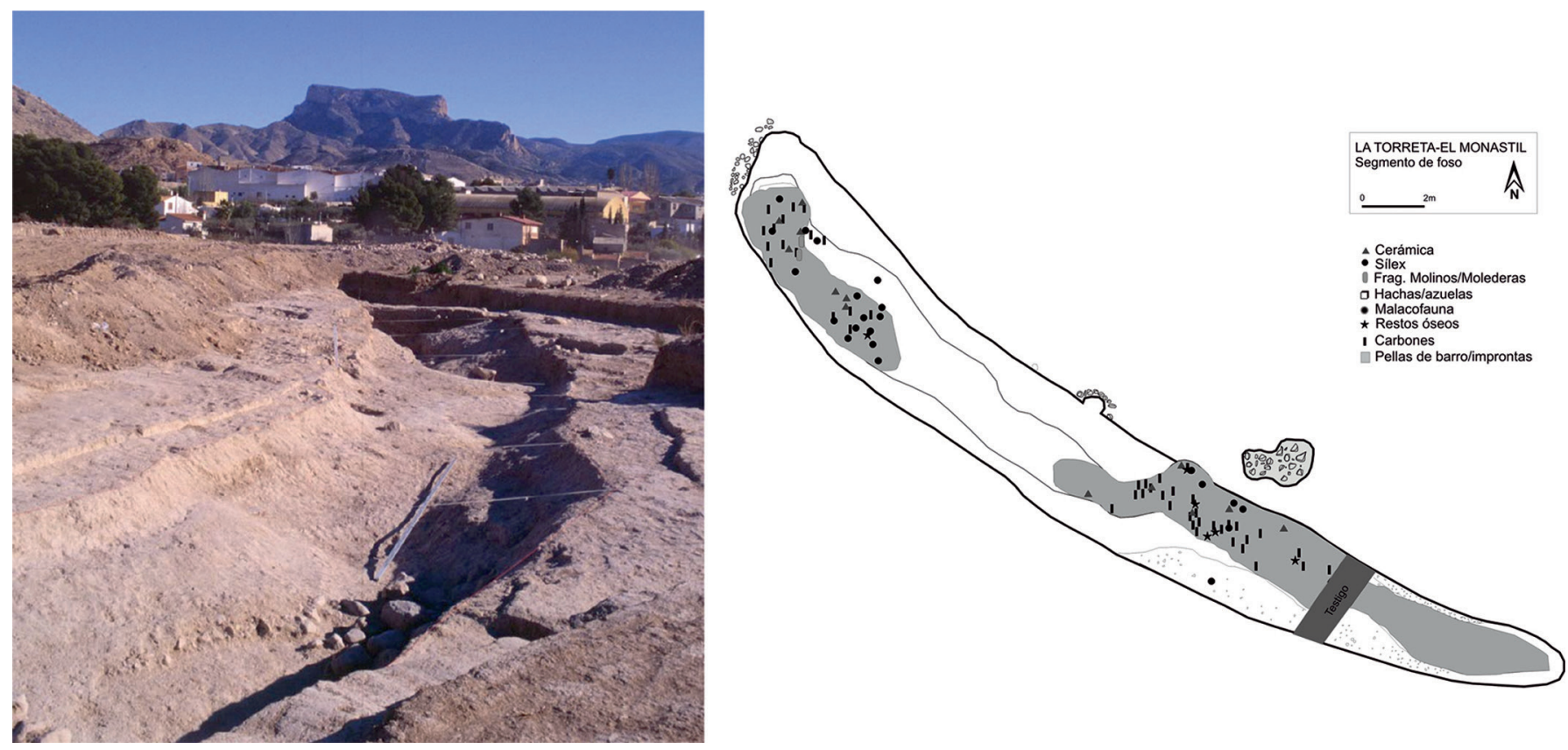

Fig. 8. Fotografía del foso de La Torreta-El Monastil y plano con la distribución general de restos arqueológicos. 


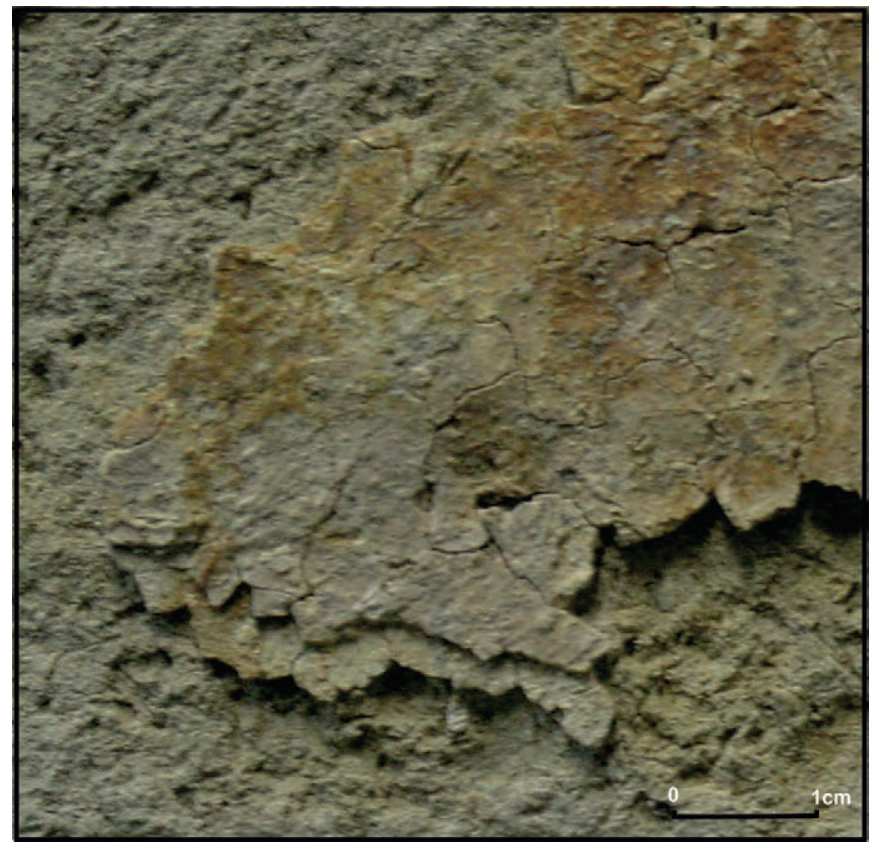

Fig. 9. Detalle fotográfico de las diferentes capas, a modo de enlucidos, conservadas en uno de los fragmentos de barro analizados de La Torreta-El Monastil.

Por un lado, las tres muestras procedentes de las UUEE de derrumbe 1063 y 1067, de la fase I o fundacional de Cabezo Pardo, presentan gran dureza, improntas negativas vegetales de caña y carrizo, marcas provocadas por insectos anélidos, restos de gasterópodos en el mortero de barro y, una de ellas, una capa de enfoscado de barro en una de sus superficies alisadas. La totalidad de las muestras estarían compuestas mayoritariamente del mineral calcita, seguido del cuarzo, según la DRX. Del mismo modo, se identificó la presencia de carbonato cálcico procedente del aragonito presente en los gasterópodos que formaban parte de los morteros de tierra.

No obstante, la cuarta muestra, procedente de la UE de derrumbe 1139 de una estancia interpretada como singular, el llamado edificio L (Fig. 10), presentaba características diferentes.

El resto constructivo de barro del que se tomó, poco cohesionado y compuesto principalmente de dolomita, presentaba una superficie alisada cubierta por un enfoscado y, sobre éste, una delgada y heterogénea capa de coloración blanquecina. En la superficie de este encalado o pintado se observan las marcas de los trazos realizados durante este proceso, posiblemente con una brocha de esparto o fibras vegetales blandas (Fig. 11). Esta fina capa estaba compuesta por dolomita y calcita. El interior del mortero de barro contenía restos orgánicos carbonizados, entre los que se identificaron semillas.
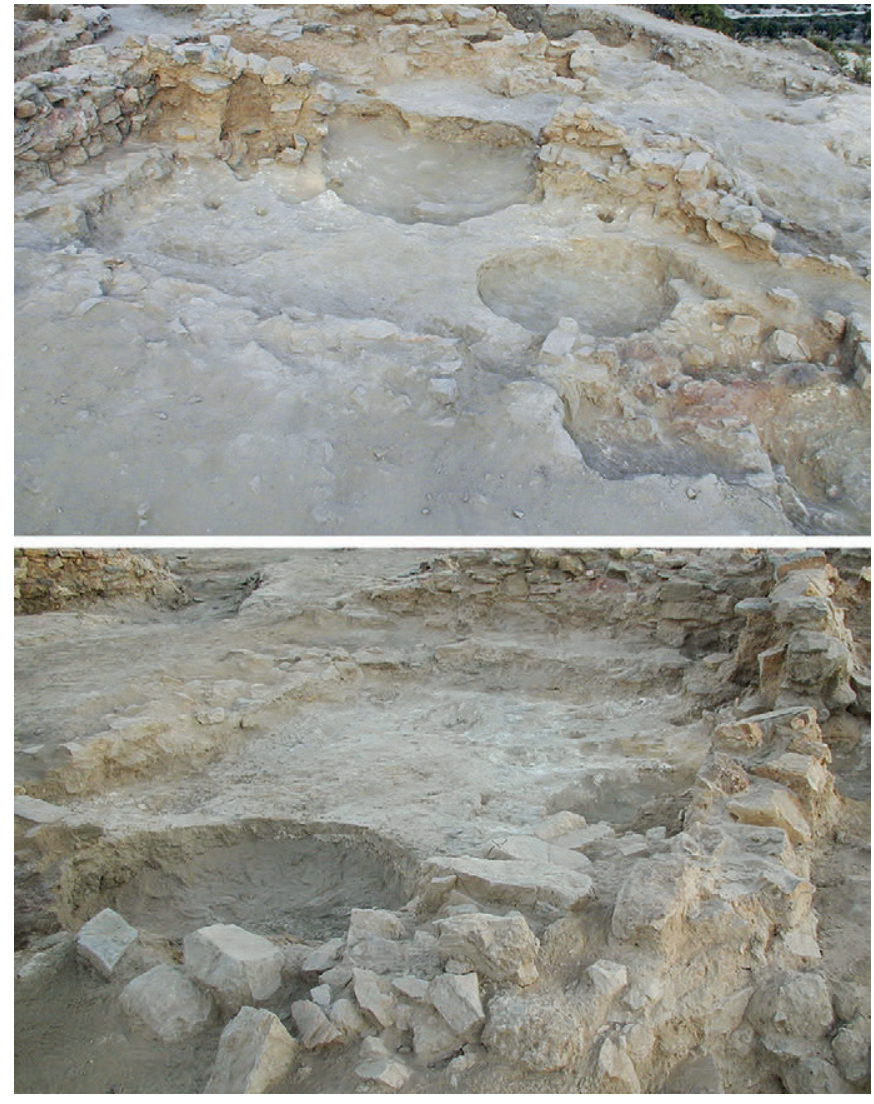

Fig. 10. Vista del interior del edificio $L$ de Cabezo Pardo (fotografías de Juan A. López Padilla. Archivo fotográfico del MARQ).

Para esta muestra y en el caso del encalado o pintado, necesariamente las dolomías utilizadas en su fabricación han tenido que sufrir un proceso pirotecnológico, puesto que no habría sido posible conseguir el mismo resultado utilizando materiales de origen geológico.

\section{DISCUSIÓN}

Con el desarrollo de la arqueología procesual en la década de 1970, en buena parte del ámbito mediterráneo y europeo, la disciplina arqueológica adquiría un perfil cientifista, gracias a la introducción del método hipotético-deductivo, metodologías científicas probabilistas y un amplio número de técnicas procedentes de las ciencias naturales, como la química. En este marco, se empezaron a efectuar un amplio y variado número de estudios analíticos de tipo arqueométrico, sobre toda clase de restos arqueológicos.

Una de las vías de investigación que se abrieron a partir de entonces fue la determinación de la presencia de cal entre los componentes de los materiales inorgánicos utilizados 


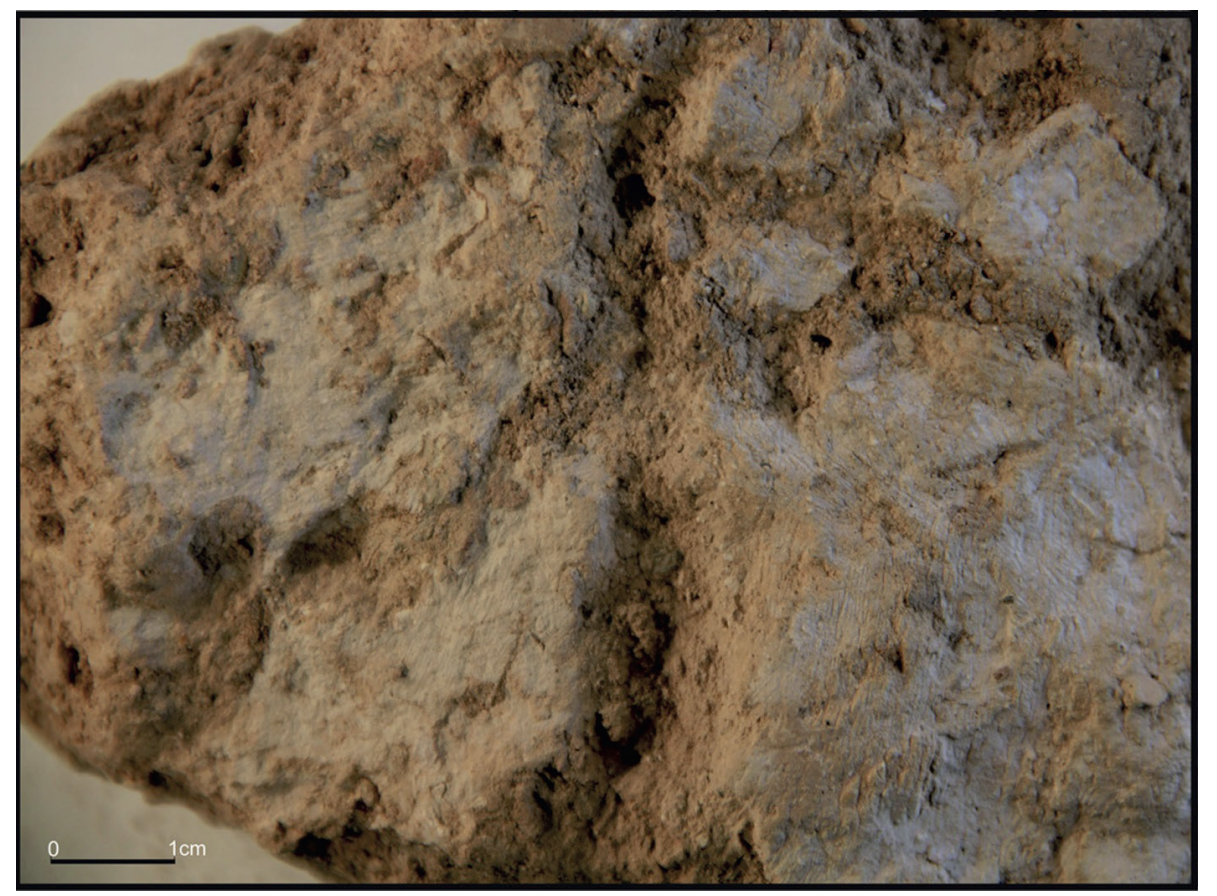

Fig. 11. Fotografía de la superficie enfoscada de un fragmento de barro de Cabezo Pardo, con marcas de la aplicación de un posible encalado (Martínez, Vilaplana, Such, Juan y García 2014: 373). en la construcción. A modo de ejemplo, la aplicación de técnicas como la DRX en yacimientos del Próximo Oriente, permitía plantear el empleo de la cal ya desde el Epipaleolítico Geométrico de Kebaran (Bar-Yosef y Goring-Morris 1977), y su empleo en el ámbito de la construcción durante la fase Natufiense (Kingery, Vandiver y Prickett 1988), servía para deducir la progresiva consolidación y sedentarización de los grupos cazadores y recolectores en vías de neolitización. Así, el empleo de esta técnica instrumental se extendió a otras zonas del Mediterráneo como la península Ibérica, aplicada en solitario (Ayala y Ortiz 1989; García, Carrión, Collado, Montero, Muñoz, Pérez, Roldán, Roman, Tormo, Verdasco y Vives-Ferrándiz 2010), o junto con otra técnica (Rivera 2007; 2009).

Unos años más tarde, se introdujo la aplicación de la microscopía al estudio de la cal en las construcciones de cronología prehistórica. La idoneidad de la aplicación de la microscopía electrónica de barrido (SEM), aplicada de forma aislada, para distinguir la presencia de cal en morteros constructivos fue puesta en duda, ya que no permite diferenciar rasgos de mayor escala del mortero, sí observables mediante microscopía de lámina delgada (Karkanas 2007: 776). A modo de ejemplo, en el asentamiento neolítico de Çatal Hüyük se determinó el empleo de la cal en los pavimentos, aplicando para ello esta técnica (Kingery, Vandiver y Prickett 1988). No obstante, la interpretación de dichos resultados fue posteriormente cuestionada. El uso de microscopía óptica petrográfica sobre las mismas muestras determinó que realmente se trataba de material calcáreo sin combustionar (Matthews, French, Lawrence y Cutler 1996).

Así, el empleo de láminas delgadas se ha aplicado al problema de la determinación de la cal en morteros prehistóricos (Goren y Goldberg 1991; Karkanas 2007; Goren y Goring-Morris 2008), así como la microscopía infrarroja (Chu, Regev, Weiner y Boaretto 2008). Estos estudios cuentan con las limitaciones inherentes al empleo de una sola técnica en aquellos trabajos de investigación que pretendían caracterizar las muestras de morteros constructivos. Es necesaria, por tanto, la aplicación de diversas técnicas de carácter complementario.

Para la Prehistoria reciente en la península Ibérica, a pesar de haberse realizado un importante número de estudios de tipo morfológico y descriptivo de fragmentos de morteros constructivos (Ayala, Rivera y Obón de Castro 1989; García López 2010; Gómez 2004, 2008, 2011; Gusi y Olària 2014; Jover 2010; Jover y Pastor 2014; Miret 1992; Pastor 2014; Rivera 2007, 2009, 2011; Sánchez 1997; 1999), no son muchos los estudios de carácter arqueométrico.

No obstante, por su singularidad y en relación al tema que nos ocupa, es necesario mencionar aquí las denominadas "tumbas-calero" del valle de Ambrona (Soria). Se trata de unos enterramientos tumulares de cronología neolítica - Peña de la Abuela y La Simacompuestos por una falsa bóveda de piedras calizas, que posteriormente habrían sido incendiados de forma 
intencional. Fruto de dicha combustión se materializó una gruesa capa de cal, que selló los mismos (Rojo, Kunst y Palomino 2002). La reproducción experimental del enterramiento de la Peña de la Abuela ha resaltado, entre otras cuestiones, la cantidad de trabajo que tuvo que ser necesario invertir en el abastecimiento y transporte de las distintas materias primas necesarias para su construcción, tarea que probablemente hubo de abordarse de forma comunal (Rojo 1999: 9). Si bien la interpretación dada a los hallazgos apunta a la producción de cal al combustionar una estructura caliza de carácter funerario, es cierto que este material no ha sido identificado mediante técnicas instrumentales como resultado de un proceso de origen antrópico. Los resultados de la reproducción experimental indican que "sólo la parte superior de la estructura se transformó en $\mathrm{CaO}$, mientras que en los dos tercios inferiores (de la estructura), sólo una pequeña capa se deshidrató suficientemente como para descomponerse en cal viva" (Rojo 1999: 8), unido esto a que, en el proceso de excavación, se documentó "una potente costra de cal de unos $20-25 \mathrm{~cm}$ de espesor y $20 \mathrm{~m}^{2}$ de superficie", cuyo levantamiento "dejó al descubierto la evidencia de un nivel de incendio en forma de capa cenicienta y restos vegetales en avanzado proceso de combustión. Paralelamente se recuperaron, en y bajo este nivel de incendio, numerosos restos humanos completamente calcinados" (Rojo 1999: 5). Ello nos induce a pensar que la capa de cal se formó a partir de la de cenizas, originada por la combustión del material vegetal de la pira, y que durante la combustión se alcanzaron temperaturas suficientes para descomponer el carbonato cálcico formado en la descomposición del oxalato cálcico de la materia vegetal. Por ello, la cal producida no tendría un origen antrópico, aunque sin los análisis pertinentes, esto no puede asegurarse. De cualquier modo, estas "tumbas-calero", sin consistir en la materialización de producción de cal para un uso al margen del funerario, podrían reforzar el planteamiento de que la tecnología de la cal se conociese en la península Ibérica durante el Neolítico, si se constatase el probable uso de la cal en más asentamientos de esa cronología.

Como ya hemos adelantado, esta cuestión no puede abordarse obviando los problemas planteados en la investigación a la hora de discriminar, en el análisis de muestras de morteros arqueológicos, entre la presencia de carbonatos cálcicos naturales y la cal. No obstante, la aplicación de forma aislada de determinadas técnicas instrumentales, más que profundizar sobre bases firmes en la resolución de dicho problema, vendría a seguir errando, no sólo en la caracterización de los morteros, sino también en las proposiciones de orden social deducibles de los mismos. Algunas técnicas, como la DRX, se siguen aplicando en solitario en la caracterización de morteros, interpretando la presencia de cal como un producto antrópicamente generado. En cuanto a algunos de los asentamientos de cronologías posteriores, correspondientes a sociedades iberas - s. IV a.C.- del Levante peninsular, como la Bastida de les Alcusses (Moixent, Valencia), son únicamente la aproximación sedimentológica y las referencias a la abundante presencia de cal en asentamientos del entorno de la misma cronología, las que argumentan la existencia y el empleo de cal de origen antrópico (Ferrer 2010), pero no la aplicación de técnicas de caracterización arqueométrica.

Por esta razón, en la línea de investigación emprendida sobre la caracterización de los materiales empleados en la construcción de momentos de la Prehistoria reciente en las tierras del Levante peninsular, hemos optado por seguir la propuesta de Middendorf, Hughes, Callebaut, Baronio y Papayianni (2005), de aplicar diversas técnicas, cuyos resultados son complementarios en buena medida. No obstante, la experiencia alcanzada con los resultados obtenidos también ha mostrado que, a pesar del protocolo instrumental aplicado, no siempre puede discriminarse el origen de los carbonatos cálcicos presentes en las muestras. Quizá, cuando el número de muestras sea más cuantioso, podrá determinarse su origen con mayor precisión.

Por el momento, y con los resultados obtenidos del análisis de un total de doce muestras procedentes de distintos yacimientos, y con una cronología que abarca desde el Neolítico a la Edad del Bronce, podemos proponer que en la zona del Levante peninsular no se fabricó y empleó la cal hasta, posiblemente, momentos avanzados del III milenio cal BC. No obstante, los primeros grupos neolíticos, implantados desde mediados del VI milenio cal BC, ya conocían las propiedades aglutinantes de la ceniza y otras materias carbonizadas, en especial si éstas procedían de estructuras de combustión elaboradas con cantos calizos, por lo que pudo darse su empleo en morteros. En cualquier caso, los datos disponibles permiten descartar que la presencia de la cal se relacione con la llegada de los fenicios a las tierras peninsulares (Díes 1994; Blázquez 2008: 26-27).

Las dos muestras analizadas del asentamiento de La Torreta-El Monastil, datado hacia mediados del III milenio cal $\mathrm{BC}$, ya permiten plantear, aunque no asegurar, el uso de la cal en el mismo. Para determinar esta cuestión sería necesario analizar un mayor número de 
muestras de fragmentos de morteros, de éste y otros yacimientos coetáneos. No obstante, otros indicadores indirectos podrían avalar la producción de cal desde, al menos, estos momentos, o incluso en fechas algo anteriores. Por un lado, consideramos un indicio de enorme importancia que en varios fragmentos constructivos, además de observarse una cara alisada, ésta está enfoscada con varias capas superpuestas de una materia cuya coloración es de tendencia blanquecina. Por otro lado, desde aproximadamente el 2800-2700 cal BC, comienza a constatarse la edificación de cabañas de tendencia circular con zócalos de piedra (Jover, García, Moratalla, Segura, Biete, Tormo y Martínez 2012). Cabría la posibilidad de que transformaciones como éstas en las técnicas constructivas vayan unidas al desarrollo de otras mejoras y, así también, a los inicios de la producción de cal antropogénica.

En cualquier caso, los análisis efectuados sobre diversos fragmentos de morteros de la primera fase del asentamiento de la Edad del Bronce de Cabezo Pardo, datada a inicios del II milenio cal BC, no muestran indicios del empleo de la cal, aunque los enfoscados del edificio $L$ de la segunda fase constructiva de este mismo poblado, ya lo evidencian.

La presencia, en varios asentamientos de la Edad del Bronce como Cabezo Redondo (Soler García 1987) o La Almoloya (Lull, Micó, Rihuete y Risch 2015), de enfoscados blanquecinos sobre morteros similares, mostraría, en caso de comprobarse que se trata de cal —en el caso del Cabezo Redondo, análisis químicos propios inéditos nos muestran hasta 10 capas de encalados en un mismo fragmento-- que la producción y uso de este producto ya se habría extendido entre las comunidades campesinas del II milenio cal BC, aunque, al parecer, solamente sería empleada en el enlucido de determinados edificios. Ello concordaría con los primeros usos de la cal en el Próximo Oriente (Kingery, Vandiver y Prickett 1988), en enlucidos, pavimentos y, con posterioridad, en morteros constructivos.

\section{CONCLUSIONES}

La aplicación de la cal a usos constructivos aporta a los morteros cohesión y resistencia, además de protección frente a la humedad interna y externa, tanto en pavimentos, como en alzados. Es un excelente estabilizante constructivo, que supondría una gran mejora en las condiciones de habitabilidad de los espacios construidos
(Guerrero 2007: 189; Guerrero, Soria y García 2010: 179). No obstante, requiere todo un proceso de elaboración previo, que supone una mayor necesidad de empleo de energía humana que la preparación y adición de otros estabilizantes a los morteros de tierra, como los vegetales, el estiércol o la ceniza.

La cal, que parece documentarse en algunas construcciones del área del Levante peninsular a partir de momentos avanzados del III milenio cal BC, se produciría, considerando los datos de los que disponemos hasta el momento, en pequeñas comunidades y para un uso doméstico, reducido al ámbito del propio lugar de hábitat. Para obtener el producto final sería necesario todo un proceso previo de trabajo, que comenzaría con la obtención de los recursos naturales necesarios para ser empleados como materias primas. Además de la propia piedra caliza, que habría de recogerse de la superficie terrestre o ser obtenida en canteras, sería necesaria una considerable cantidad de combustible, generalmente madera, aunque también puede emplearse estiércol para este fin, previamente secado al sol (Aurenche y Maréchal 1985: 405). La cantidad considerable de madera necesaria para la producción de cal se añadiría a la ya requerida por otras actividades, como la alimentación, la obtención de calor o la construcción.

Por tanto, la producción de cal y su uso extendido en la sociedad supone un cambio en la relación de las comunidades campesinas con el medio natural en el que viven, ya que requiere de una mayor inversión laboral y una mayor incidencia antrópica sobre el medio vegetal del entorno de los asentamientos, aspecto que, a nuestro juicio, debería comenzar a valorarse en mayor medida, en relación con la incidencia del impacto humano sobre el medio. Pero, al mismo tiempo, también implica un cambio en las relaciones sociales, ya que con su empleo se consiguen construcciones más estables y duraderas, afianzando la transmisión generacional de los espacios residenciales y, por extensión, la transmisión de la propiedad.

Por otro lado, la piedra caliza pudo calcinarse, en un primer momento, quizá accidentalmente, en estructuras de combustión destinadas a otras funciones, como la cocción cerámica. La producción de cal también pudo comenzar a desarrollarse a raíz de que las comunidades comprobaran la reacción del agua al contacto con piedras calizas expuestas a altas temperaturas, que se utilizaran para cocinar sobre ellas (Carran, Hughes, Leslie y Kennedy 2011: 118; Villaseñor y Barba 2012: 14). No obstante, la obtención de la cal en sí requiere una 
calcinación completa y continuada del material pétreo a muy altas temperaturas, por lo que hubo de obtenerse en hornos fabricados para este propósito, posiblemente de tamaño reducido y al aire libre. Estos hornos podrían consistir en agujeros excavados en el suelo (Garfinkel 1987: 71), revestidos con una capa de mortero arcilloso, en los que introducir la piedra a combustionar, cuando no en simples hogueras (Brysbaert 2007: 34). Estas materias primas habrían de transportarse hasta el lugar de cocción continuada de la roca y prepararse para un proceso de producción que requeriría el trabajo de una parte del grupo humano durante días. Terminada la cocción, el horno se dejaría enfriar para que la cal pudiera ser apagada y mezclada, para su aplicación, con el resto de componentes del mortero.

En cualquier caso, la identificación del uso constructivo de la cal en un asentamiento no implica su empleo en la mayoría de las estructuras edificadas, sino que su aplicación durante la Prehistoria reciente en el Este peninsular parece estar desigualmente distribuida dentro de los asentamientos. Por el momento, el empleo de cal durante el II milenio cal BC sólo se constata en algunas de las construcciones de determinados núcleos, lo que puede estar relacionado con la diferente funcionalidad de las estructuras —edificios singulares, hábitat, almacenaje, etc.-, así como con su relevancia social (Garfinkel 1987).

En definitiva, consideramos que comenzamos a dar los primeros pasos en el conocimiento de los inicios del empleo de la cal para labores constructivas en la península Ibérica. Con los resultados presentados se empieza a concretar a partir de qué momento, y en relación con qué proceso histórico, se relaciona la introducción de mejoras en las condiciones materiales de vida que su producción pudo implicar, sin perder de vista las dificultades todavía existentes en la caracterización de morteros prehistóricos. Futuros trabajos con bases empíricas más amplias permitirán profundizar en los diferentes aspectos analizados.

\section{AGRADECIMIENTOS}

Queremos agradecer al personal de los Servicios Técnicos de la Universidad de Alicante su disposición y ayuda a la hora de realizar los análisis de las muestras.

También agradecer a Palmira Torregrosa Giménez, Juan Antonio López Padilla y a la empresa Alebus Patrimonio Histórico S.L.U. la cesión de materiales para su estudio y publicación.

\section{BIBLIOGRAFÍA}

Aurenche, O. 1981: La maison orientale. L'architecture du Proche Orient ancien des origines au milieu du Ivème millénaire, Tome 1, Institut Francais d'Archeologie du Proche Orient, Paris.

Aurenche, O. y Maréchal, C. 1985: "Note sur la fabrication actuelle du plâtre à Qdeir (Syrie)", Cahiers de l'Euphrate, 4, 221228.

Ayala Juan, M. M, Rivera Núñez, D. y Obón de Castro, C. 1989: “Improntas vegetales de adobes procedentes de la casa A del yacimiento argárico en llanura de Rincón de Almendricos, Lorca, Murcia”, Crónica del XIX Congreso Arqueológico Nacional (Castellón, 1987), 1, 279-291, Zaragoza.

Ayala Juan, M. M. y Ortiz González, R. 1989: “Análisis por difracción de rayos $\mathrm{X}$ de enlucidos de las casas argáricas de los yacimientos el Rincón de Almendricos y el Cerro de las Viñas de Coy, Lorca", Crónica del XIX Congreso Arqueológico Nacional (Castellón, 1987), 1, 323-328, Zaragoza.

Bar-Yosef, O. y Goring-Morris, A. N. 1977: "Geometric Kebaran Occurrences”, en O. Bar-Yosef y J. L. Phillips, Prehistoric Investigations in Gebel Maghara, Northern Sinai, Qedem 7, Monographs of the Institute of Archaeology, 331-368, The Hebrew University, Jerusalem.

Bardou, P. y Arzoumanian, V. 1986: Arquitecturas de adobe, Gustavo Gili, México DF.

Bernabeu Auban, J. (dir.) 1993: "El III milenio a. C. en el País Valenciano. Los poblados de Jovades (Cocentaina, Alacant) y Arenal de la Costa (Ontinyent, València)", Saguntum PLAV, 26, 9-180.

Bernabeu Auban, J., Barton, C.M., Pardo Gordó, S. y Bergin, S. M. 2015: "Modeling initial Neolithic dispersal. The first agricultural groups in West mediterranean", Ecological Modelling, 307, 22-31.

Bernabeu Auban, J., Molina Balaguer, L., Diez Castillo, A. y Orozco-Köhler, T. 2006: "Inequialities and power. Three millennia of Prehistory in Mediterranean Spain (5600-2000 cal BC)”, en Díaz-del Rio P., García Sanjuán, L. (eds.), Inequality in Iberian Late Prehistory, BAR International Series 1525, 97-116, Oxford.

Bernabeu Auban J., Molina Balaguer, L., Orozco- Köhler, T. y Diez Castillo, A. 2008: "Early neolithic at the Serpis Valley, Alicante, Spain", en Diniz, M. (ed.), The early Neolithic in the Iberian Peninsula. Regional and transregional components, BAR International Series 1857, 53-59, Oxford.

Bernabeu Auban, J., Orozco- Köhler, T., Diez Castillo, A., Gómez Puche, M. y Molina Hernández, F. J. 2003: "Mas d'Is (Penáguila, Alicante). Aldeas y recintos monumentales del Neolítico Inicial en el valle del Serpis", Trabajos de Prehistoria, 60, 2, 39-59.

Bish, D. L. y Duffy, C. J. 1990: "Thermogravimetric analysis of minerals", en J. W. Stucki y D. L. Bish (eds.), Thermal Analysis in Clay Science, 96-157, Boulder.

Blázquez Martínez, J. M. 2008: "Últimas aportaciones a la presencia fenicia cartaginesa en Occidente. Arquitectura y urbanismo", Gerión, 26-2, 9-73.

Boynton, R. S. 1980: Chemistry and Technology of Lime and Limestone, Wiley-Interscience, New York.

Bronk Ramsey, C. y Lee, S. 2013: "Recent and Planned Developments of the Program OxCal”. Radiocarbon, 55(2-3): 720-730.

Brysbaert, A. 2007: "Murex uses in plaster features in the Aegean and Eastern Mediterranean Bronze Age", Mediterranean Archaeology and Archaeometry $7,2,29-51$.

Carran, D., Hughes, J., Leslie, A. y Kennedy, C. 2011: “A Short History of the Use of Lime as a Building Material Beyond Europe and North America", International Journal of Architectural Heritage, 6, 2, 117-146.

Chu, V., Regev, L., Weiner, S. y Boaretto, E. 2008: "Differentiating between anthropogenic calcite in plaster, ash and natural calcite using infrared spectroscopy: implications in archaeology", Journal of Archaeological Science, 35, 905-911.

Daneels, A. y Guerrero Baca, L. F. 2011: "Millenary earthen architecture in the tropical lowlands of Mexico", APT Bulletin 42, 1, 11-18.

Daneels, A. y Guerrero Baca, L, F. 2013: "Rescate de estructuras prehispánicas de barro crudo en la costa veracruzana, México", en Construcción con tierra. Pasado, presente y futuro. Congreso de Arquitectura de tierra en Cuenca de Campos 2012. [online],17-26, Universidad de Valladolid, Valladolid. 
De Chazelles Gazzal, C. A. y Klein, A. 2003: Échanges transdisciplinaires sur les constructions en terre crue, Actes de la table-ronde de Montpellier, 17-18 novembre 2001, Éd. de l'Espérou, Montpellier.

De Chazelles Gazzal, C. A. y Poupet, D. 1985: "La fouille des structures de terre crue. Définitions et difficultés", Aquitania 3, 149-160.

De Chazelles Gazzal, C. A., Klein, A. y Pousthomis, N. 2011: Les cultures constructives de la brique crue. Troisièmes Échanges transdisciplinaires sur les constructions en terre crue, Éd. de l'Espérou, Montpellier.

De Pedro Michó, M. J. 1998: La Lloma de Betxí (Paterna, Valencia). Un poblado de la Edad del Bronce, Serie de Trabajos Varios, SIP (Servicio de Investigación Prehistórica de Valencia) 94, Diputación de Valencia, Valencia.

Díes Cusí, E. 1994: La arquitectura fenicia de la Península Ibérica y su influencia en las culturas indigenas. Tesis doctoral, Universidad de Valencia, Valencia.

Ferrer García, C. 2010: "Los adobes y la arquitectura del barro en la Bastida de les Alcusses (Moixent, Valencia). Una aproximación desde el análisis sedimentológico", Archivo de Prehistoria Levantina, vol. XXVIII, 273-300.

Frierman, J. D. 1971: "Lime burning as the precursor of fired ceramics", Israel Exploration Journal, 21, 212-216.

Gama-Castro, J. E., Cruz y Cruz, T., Pi-Puig, T., Alcalá-Martínez, R., Cabadas-Báez, H., Jasso-Castañeda, C., Díaz-Ortega, J., Sánchez-Pérez, S., López-Aguilar, F. y Vilanova de Allende, R. 2012: "Arquitectura de tierra: el adobe como material de construcción en la época prehispánica”, Boletín de la Sociedad Geológica Mexicana 64, 2, 177-188.

García Atiénzar, G., 2009: Territorio Neolítico. Las primeras comunidades campesinas en la fachada oriental de la peninsula Ibérica (ca. 5600-2800 cal BC), British Archaeological Reports, I.S. 2021, Oxford.

García Atiénzar, G., 2014: "Primeras aportaciones del proyecto de excavaciones arqueológicas en el poblado campaniforme del Peñón de la Zorra (Villena, Alicante)", II Jornadas de Arqueología y patrimonio alicantino. Marq, Arqueología y Museos, Extra 1, 196-201.

García Atiénzar, G. y Jover Maestre, F. J., 2011: "The introduction of the first farming communities in the western Mediterranean: the valencian region in Spain as example", Arqueología Iberoamericana, 10, 17-29.

García López, E. 2010: "Restes de fang neolítiques. Morfologia e interpretació dels elements documentats a la mina 84 de Gavà", Rubricatum 4, 97-108.

García Borja, P., Carrión Marco, Y., Collado Beneyto, I., Montero Ruiz, I., Muñoz Abril, M., Pérez Jordá, G., Roldán García, C., Roman Monroig, D., Tormo Cuñat, C., Verdasco Cebrián, C. y Vives-Ferrándiz, J. 2010: "Campaña de excavación arqueológica de urgencia en Caramoro II (Elx, Alacant)", Marq, Arqueología y Museos, 4, 37-66.

Garfinkel, Y. 1987: "Burnt Lime Products and Social Implications in the Pre-Pottery Neolithic B Villages of the Near East", Paléorient 13, 1, 69-76.

Gómez Puche, M. 2004: "Estudio de los fragmentos de barro cocido en el yacimiento de la "Illeta dels Banyets" (El Campello, Alicante)", en Soler Díaz, J. A., La ocupación prehistórica de la Illeta dels Banyets (El Campello, Alicante), 271-280, Diputación de Alicante-MARQ, Alicante.

Gómez Puche, M. 2008: "Contribución al conocimiento de los asentamientos neolíticos: análisis de los elementos de barro", en Hernández Pérez, M.S., Soler Díaz, J.A., López Padilla, J.A. (eds.), Actas del IV Congreso del Neolitico Peninsular (Alicante, 2006), 2, 200-209, Diputación de AlicanteMARQ, Alicante.

Gómez Puche, M. 2011: "El barro cocido", en Pérez Jordá, G., Bernabeu Aubán, J., Carrión Marco, Y., García Puchol, O., Molina Balaguer, L., Gómez Puche, M., La Vital (Gandia, Valencia): vida y muerte en la desembocadura del Serpis durante el III y el I milenio a.C., Serie de Trabajos Varios, SIP (Servicio de Investigación Prehistórica de Valencia), 113, 229-234, Diputación de Valencia, Valencia.

Goren, Y. y Goldberg, P. 1991: "Petrographic thin sections and the development of Neolithic plaster production in Northern Israel", Journal of field Archaeology, 18, 131-138.

Goren, Y. y Goring-Morris, A. N. 2008: "Early pyrotechnology in the Near East: experimental lime-plaster production at the Pre-Pottery Neolithic B site of Kfar HaHoresh, Israel", Geoarchaeology: An International Journal, 23 (6), 779-798.

Guerrero Baca, L. F. 2007: "Arquitectura en tierra. Hacia la recuperación de una cultura constructiva", Apuntes 2, 2, 182-201.
Guerrero Baca, L. F., Soria, J. y García, B. 2010: "La cal en el diseño y conservación de arquitectura de tierra", en Maldonado Ramos, L., Rivera Gámez, D., Vela Cossío, F. (eds.), Arquitectura construida en tierra, Tradición e Innovación. Congresos de Arquitectura de Tierra en Cuenca de Campos 2004/2009 (online): 177-186, Universidad de Valladolid, Valladolid.

Gusi Jener, F. y Olària Puyoles, C. 2014: Un poblado fortificado del Bronce medio y Bronce Final en el litoral Mediterráneo: Orpesa la Vella (Orpesa del Mar, Castellón, España), Monografies de Prehistòria i Arqueologia Castellonenques, 10, Servei d'investigacions Arqueològiques i Prehistòriques, Castellón.

Hobbs, L. W. y Siddall, R. 2011: "Cementitious materials of the ancient world”, en Ringbom, Å., Hohlfelder, R. L. (eds.), Building Roma aeterna: current research on Roman mortar and concrete, The Finnish Society of Sciences and Letters 128, 35-60, Helsinki.

Jover Maestre, F. J. (coord.) 2010: La Torreta-El Monastil (Elda, Alicante): del IV al III milenio AC en la cuenca del río Vinalopó, Memorias Excavaciones Arqueológicas 5, Diputación de Alicante-MARQ, Alicante.

Jover Maestre, F. J. 2013: "Las áreas de actividad y las unidades domésticas como unidades de observación de lo social: de las sociedades cazadorasrecolectoras a las agricultoras en el este de la península Ibérica", en Gutiérrez, S., Grau, I., (eds.), De la estructura doméstica al espacio social. Lecturas arqueológicas del uso social del espacio, 13-38, Universidad de Alicante, Alicante.

Jover Maestre, F.J., García Atiénzar, G., Moratalla Jávega, J., Segura Herrero, G., Biete Bañón, C., Tormo Cuñat, C. y Martínez Monleón, S. 2012: "Continuidad residencial e intensificación productiva durante la primera mitad del III milenio cal BC en el Levante de la península Ibérica: las aportaciones del asentamiento de El Prado (Jumilla, Murcia)", Revista Atlántica-Mediterránea de Prehistoria y Arqueología Social, 14, 15-54.

Jover Maestre, F. J. y López Padilla, J. A. 1997: Arqueología de la muerte. Prácticas funerarias en los límites de El Argar, Universidad de Alicante, Alicante.

Jover Maestre, F. J. y López Padilla, J.A. 2009: "Más allá de los confines del Argar. Los inicios de la Edad del Bronce y la delimitación de las áreas culturales en el cuadrante suroriental de la península Ibérica, 60 años después", en Hernández Pérez, M.S., López Padilla, J.A., Soler Díaz, J. A. (eds.), En los confines del Argar. Una cultura de la Edad del Bronce en Alicante, 268-292, Diputación de Alicante-MARQ, Alicante.

Jover Maestre, F. J. y Pastor Quiles, M. 2014: "La edificación con tierra: las evidencias constructivas en Galanet", en F. J. Jover Maestre, P. Torregrosa Giménez y G. García Atiénzar, (eds.), El Neolítico en el Bajo Vinalopó (Alicante, España), BAR International Series 2646, 209-214, Oxford.

Jover Maestre, F. J., López Padilla, J. A. y García-Donato, G. 2014: "Radiocarbono y estadística bayesiana. Aportaciones a la cronología de la Edad del Bronce en el extremo oriental del sudeste de la península Ibérica", Saguntum, 46, 41-69.

Jover Maestre, F. J., Torregrosa Giménez, P. y García Atiénzar, G. 2014: El Neolítico en el Bajo Vinalopó (Alicante, España), BAR International Series 2646, Oxford.

Karkanas, P. 2007: "Identification of lime plaster in Prehistory using petrographic methods: A review and reconsideration of the data on the basis of experimental case studies", Geoarchaeology: An International Journal, 22, 7, 775-796

Karkanas, P. y Stratouli, G. 2008: "Neolitic Lime Plastered Floors in Drakaina Cave, Khephalonia Island, Western Greece: Evidence of the significance of the site", The Annual of British School at Athens, 103, 27-41.

Kingery, W. D., Vandiver, P. B. y Prickett, M. 1988: "The beginnings of Pyrotechnology, Part II: Production and use of lime and gypsum plaster in the Pre-Pottery Neolithic Near East", Journal of Field Archaeology 15, 219-244.

López Padilla, J. A. 2009: "El grupo argárico en los confines orientales de El Argar", en Hernández Pérez, M.S., López Padilla, J.A., Soler Díaz, J.A. (eds.), En los confines del Argar. Una cultura de la Edad del Bronce en Alicante, 247-267, Diputación de Alicante-MARQ, Alicante.

López Padilla, J. A. 2014: Cabezo Pardo (San Isidro/Granja de Rocamora, Alicante). Excavaciones en el poblado de la Edad del Bronce. Serie Excavaciones Arqueológicas, Memorias, 9, Diputación de Alicante- MARQ, Alicante. 
Lull Santiago, V., Micó Pérez, R., Rihuete Herrada, C. y Risch, R. 2015: “La Almoloya. Primer palais de l'âge du Bronze occidental", Archéologia, 530, 58-63.

Machado Yanes, M. C., Jover Maestre, F. J. y López Padilla, J. A. 2009: "Antracología y paleoecología en el cuadrante suroriental de la península Ibérica: las aportaciones del yacimiento de la Edad del Bronce de Terlinques (Villena, Alicante)", Trabajos de Prehistoria, 66, 1, 75-96.

Maldonado Ramos, L. y Vela Cossío, F. 2011: "El patrimonio arquitectónico construido con tierra. Las aportaciones historiográficas y el reconocimiento de sus valores en el contexto de la arquitectura popular española", Informes de la construcción 63, 523, 71-80.

Matthews, W., French, C., Lawrence, T. y Cutler, D. 1996: "Multiple surfaces: The micromorphology", en Hodder, I. (ed.), On the surface: Catalhoyuk 1993-95, The MacDonald Institute for Research and British Institute of Archaeology of Ankara,, 301-342, Cambridge.

Martí Oliver, B. y Bernabeu Auban, J. 2012: "La vida doméstica en el Neolítico peninsular: los lugares de asentamiento", en Rojo Guerra, M., Garrido Pena, R., García Martínez De Lagrán, I. (coords.), El Neolítico en la península Ibérica y su contexto Europeo, 129-142, Cátedra, Madrid.

Martínez Mira, I., Vilaplana Ortego, E. y Jover Maestre, F. J. 2009: “Análisis mediante diferentes técnicas instrumentales (FRX, DRX, FTIR-IR, TGATD, SEM-EDAX) de dos fragmentos constructivos procedentes del yacimiento de La Torreta-El Monastil (Elda-Alicante)", en Martín Martínez, J.M. (ed.), Tendencias en adhesión y adhesivos. Bioadhesión, Bioahesivos $y$ Adhesivos Naturales, Universidad de Alicante, Alicante.

Martínez Mira, I. y Vilaplana Ortego, E. 2010: ”Dos fragmentos constructivos procedentes del yacimiento de la Torreta-El Monastil (Elda, Alicante): análisis mediante diferentes técnicas instrumentales (FRX, DRX, FTIRIR, TG-ATD, SEM-EDX)", en Jover Maestre, F. J. (coord.), La Torreta-El Monastil (Elda, Alicante): del IV al III milenio a. C en la cuenca del Vinalopó, Series Excavaciones Arqueológicas 5, Diputación de AlicanteMARQ, Alicante.

Martínez Mira, I., Vilaplana Ortego, E., Such Basánez, I., García del Cura, Ma. A. y 2011: "Análisis instrumental del recubrimiento de las paredes internas de dos estructuras negativas de tipo silo de la ocupación neolítica postcardial de Benàmer", en Torregrosa Giménez, P., Jover Maestre, F. J., López Seguí, E. (dirs.), Benàmer (Muro d'Alcoi, Alicante) Mesolíticos y neolíticos en las tierras meridionales valencianas, Serie de Trabajos Varios SIP (Servicio de Investigación Prehistórica de Valencia), 112, Diputación de Valencia, Valencia.

Martínez Mira, I., Vilaplana Ortego, E., Juan Juan, J., Such Basáñez, I. y Cazorla Amorós, D. 2012: "Estudio de materiales de construcción neolíticos mediante diferentes técnicas instrumentales", XII Congreso Nacional de Materiales - XII Congreso Iberoamericano de materiales (30 y 13 de mayo $y 1$ de junio de 2012), Universidad de Alicante, Alicante.

Martínez Mira, I., Vilaplana Ortego, E., Such Basáñez, I., Juan Juan, J. y García Del Cura, Ma. A. 2014: "Cabezo Pardo. Análisis instrumental de materiales de construcción de barro del yacimiento argárico", en LÓPEZ PADILLA, J. A (coord.): Cabezo Pardo (San Isidro/Granja de Rocamora). Excavaciones arqueológicas en el yacimiento de la Edad del Bronce, Memorias Excavaciones Arqueológicas 6, Diputación de Alicante-MARQ, Alicante.

Middendorf, B., Hughes, J., Callebaut, K., Baronio, G. y Papayianni, I. 2005: "Investigative methods for the Characterization of Historic Mortars- Part 1: Mineralogical Characterization", Materials and Structures, 38, 761-769.

Miret i Mestre, J. 1992: "Bòbila Madurell 1987-88. Estudi dels tovots i les argiles endurides pel foc», Arraona, II, 67-72.

Nandris, J. G. 1988: “The Earliest European Plaster Pyrotechnology: The red floors of Lepenski Vir", Rivista di archeologia, 12, 14-15.

Pastor Quiles, M. 2014: "Cabezo Pardo. Contribución a las formas constructivas de un hábitat argárico a partir del estudio de los elementos de barro", en López Padilla, J. A (coord.), Cabezo Pardo (San Isidro/ Granja de Rocamora, Alicante). Excavaciones arqueológicas en el yacimiento de la Edad del Bronce, 306-321, Memorias Excavaciones Arqueológicas 6, Diputación de Alicante-MARQ, Alicante.

Philokyprou, M. 2012: "The beginning of Pyrotechnology in Cyprus", International Journal of Architectural Heritage, 6, 172-199.
Regev, L., Poduska, K. M., Addadi, L., Weiner, S. y Boaretto, E. 2010: "Distinguishing between calcites formed by different mechanisms using infrared spectrometry: archaeological applications", Journal of Archaeological Science, 37, 12, 3022-3029.

Reimer, P.J., Bard, E., Bayliss, A., Beck, J. W., Blackwell, P. G., Bronk Ramsey, C., Buck, C. E., Cheng, H., Edwards, R. L., Friedrich, M., Grootes, P. M., Guilderson, T. P., Haflidason, H., Hajdas, I., Hatté, C., Heaton, T. J., Hoffmann, D. L., Hogg, A. G., Hughen, K. A., Kaiser, K. F., Kromer, B., Manning, S. W., Niu, M., Reimer, R. W., Richards, D. A., Scott, E. M., Southon, J. R., Staff, R. A., Turney, C. S. M. y Van der Plicht, J. 2013: "IntCal13 and Marine13 Radiocarbon Age Calibration Curves 0-50,000 Years cal BP”. Radiocarbon, 55 (4): 1869-1887.

Rivera Groennou, J. M 2007: "Aproximación a las formas constructivas en una comunidad de la Edad del Bronce: El poblado argárico de Peñalosa (Baños de la Encina, Jaén)", Arqueología y territorio 4, 5-21.

Rivera Groennou, J. M. 2009: "Micromorfología e interpretación arqueológica: aportes desde el estudio de los restos constructivos de un yacimiento argárico en el Alto Guadalquivir, Peñalosa (Baños de la Encina, Jaén)”, Cuadernos de prehistoria y arqueología de la Universidad de Granada 19, 339-360.

Rivera Groennou, J. M. 2011: “Téenicas constructivas y relaciones sociales en una comunidad argárica del alto Guadalquivir, Peñalosa (Baños de la Encina, Jaén)", en Memorial Luis Siret, I Congreso de Prehistoria de Andalucía, La tutela del patrimonio prehistórico, Junta de Andalucía, Consejería de Cultura, Sevilla.

Rodríguez-Navarro, C. 2012: "Binders in historical buildings: traditional lime in conservation", Seminarios de la Sociedad Española de Mineralogía (SEM) 9, 91-112.

Rojo Guerra, M. A. 1999: "Proyecto de Arqueología Experimental. Construcción e incendio de una tumba monumental neolítica a partir de los datos obtenidos en la excavación de La Peña de La Abuela”, Boletín de Arqueología Experimental 3, 5-11.

Rojo Guerra, M.A., Kunst, M. y Palomino Lázaro, A. L. 2002: "El fuego como procedimiento de clausura en tres tumbas monumentales de la Submeseta norte", en M. A. Rojo Guerra y M. Kunst (eds.), Sobre el Significado del Fuego en los Rituales Funerarios del Neolítico, Studia Archaeologica 91, 21-38, Valladolid.

Rosser Limiñana, P. y Fuentes Mascarell, C. (coords.) 2007: Tossal de les Basses. Seis mil años de historia de Alicante. Ayto. de Alicante, Alicante.

Russell, B. W. y Dahlin, B. H. 2007: "Traditional Burnt-Lime Production at Mayapán, Mexico", Journal of Field Archaeology, 32.

Rusu, A. 2011: "Lepenski Vir-Schela Cladovei Culture's. Chronology and its Interpretation", Brukenthal. Acta Musei, VI 1, 7-22.

Sánchez García, A. 1997: "La arquitectura del barro en el Vinalopó durante la Prehistoria reciente y la Protohistoria: metodología y síntesis arqueológica”, en Rico, M.C., Pérez, T., Jover Maestre, F.J., Payá, C., Hernández, L., Rojas, A. (coords.), Agua y territorio. I Congreso de estudios del Vinalopó (Petrer-Villena, 1997), 1, 139-162. CaixaPetrer, Ayuntamiento de Petrer, Ayuntamiento de Villena, Petrer-Villena.

Sánchez García, A. 1999: "Elementos arquitectónicos de barro de un poblado prehistórico: Los Almadenes (Hellín, Albacete)", XXIV Congreso Nacional de Arqueología (Cartagena, 1997), 3, 221-232, Instituto de Patrimonio Histórico, Gobierno de Murcia, Murcia.

Soler Díaz, J. A. 2006: La ocupación prehistórica de la Illeta dels Banyets, Serie Mayor 5, Diputación de Alicante-MARQ Alicante.

Soler García, J. M. 1987: Excavaciones arqueológicas en el Cabezo Redon$d o$, Instituto de Cultura Juan Gil-Albert, Alicante.

Torregrosa Giménez, P., Jover Maestre, F. J. y López Seguí, E. 2011: Benàmer (Muro d'Alcoi). Mesolíticos y neolíticos en las tierras meridionales valencianas, Serie de Trabajos Varios del SIP (Servicio de Investigación Prehistórica de Valencia), 112, Diputación de Valencia, Valencia.

Vela Cossío, F. 2003: "Investigación arqueológica y construcción con tierra en la Península Ibérica”, Actas del II Seminario Iberoamericano de Construcción con Tierra, 1-15, Mairea, Madrid.

Vilaplana Ortego, E., Martínez Mira, I., Such Basáñez, I. y Juan Juan, J. 2011: "Presencia de carbonato cálcico (CACO3) recarbonatado en un probable 
fragmento constructivo de la ocupación neolítica cardial de Benàmer", en Torregrosa Giménez, P., Jover Maestre, F. J., López Seguí, E. (dirs.), Benàmer (Muro d'Alcoi, Alicante) Mesolíticos y neolíticos en las tierras meridionales valencianas, Serie de Trabajos Varios SIP (Servicio de Investigación Prehistórica de Valencia), 112, Diputación de Valencia.

Vilaplana Ortego, E., Martínez Mira, I., Juan Juan, J., Such Basañez, I. y Cazorla Amorós, D. 2012: "Nueva aplicación potencial de dos técnicas instrumentales para la caracterización de materiales de construcción prehistóricos", XII Congreso Nacional de Materiales - XII Congreso Iberoamericano de materiales, (30 y 31 mayo y 1 de junio de 2012, Universidad de Alicante, Alicante.

Vilaplana Ortego, E., Martínez Mira, I., Such Basañez, I., Juan Juan, J. y García Del Cura, Ma . A. 2014: “Galanet (Elx, Alicante): Análisis químico instrumental de los materiales de construcción", en Jover Maestre, F.J., Torregrosa Giménez, P., García Atiénzar, G. (eds.), El Neolítico en el Bajo Vinalopó (Alicante, España), BAR International Series, 209-214, Oxford.

Villaseñor Alonso, I. y Barba Pingarrón, L. 2012: "Los orígenes tecnológicos de la cal", Cuicuilco 55, 11- 41.

Viñuales, G. M., Martins Neves, C. M, Flores, M. y Silvio Ríos, L. 2003: Arquitecturas de tierra en Iberoamérica, Versión digitalizada, CYTED, HABYTED, HABITERRA, PROTERRA, Salvador (Brasil).

Webb, T. L. y Krüger, J. E. 1970: "Carbonates”, en Makenzie, R.C., Differential Thermal Analysis. Vol. 1. Fundamental Aspects, 303-341, London.

Weiner, S. 2010: Microarchaeology. Beyond the visible archaeological record, Cambridge.

Wendlant, W. W. 1986: Thermal Analysis, New York. 